\title{
Nuevos apuntes sobre la reforma administrativa española de los años cincuenta
}

\section{Luis Fernando Crespo Montes}

\section{Introducción}

La reforma administrativa iniciada en nuestro país en los primeros meses de 1957, y su patrocinador, el joven catedrático de Derecho Administrativo, Laureano López Rodó, han sido objeto de numerosos estudios y comentarios no exentos, en muchos casos, de importantes prejuicios a favor o en contra.

Las valoraciones e interpretaciones políticas que se han dado sobre el significado que tuvo aquel movimiento y los propósitos de su principal líder son variadas y distintas, aunque muchas de ellas no sean excluyentes. Pero sí hay una opinión bastante generalizada en reconocer que fue el intento más consistente y efectivo de todas las reformas emprendidas en nuestra Administración durante la segunda mitad del siglo XX. Y

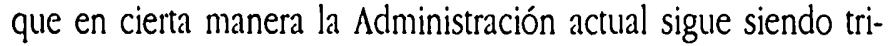
butaria, con sus virtudes y sus defectos, con ligeros retoques e imprescindibles adaptaciones, de muchos de los principios y esquemas que emergieron a partir de los últimos años cincuenta y los primeros de la década siguiente.

No se trata de hacer aquí una conmemoración halagadora ni un festival desmitificador de la reforma administrativa que promovió el profesor lópez Rodó. Tampoco de insistir en los méritos o errores de las actuaciones que fueron emprendidas, ni de las intenciones personales o de grupo, políticas o profesionales, explícitas o implicitas, que animaban a quienes dirigieron entonces o simplemente participaron en el proceso de reforma administrativa. En esta materia cada uno suele tener su a priori y ha sacado sus propias conclusiones.
El propósito de estas páginas pretende ser más objetivo, y si cabe, imparcial: recordar el contexto político concreto en que surgió, así como relatar los principales acontecimientos que tuvieron lugar, a la luz de documentos poco conocidos o ya casi olvidados. Y sin embargo útiles para recomponer los perfiles de las personas y las circunstancias en que ocurrieron los hechos. El transcurso de más de cuarenta años favorece una visión retrospectiva desde una perspectiva quizás más sosegada.

Y todo ello con una limitación en cuanto al ámbito de actuación de aquella reforma, centrado principalmente en el plano legislativo. Esto es, en el análisis de los procesos de preparación y aprobación de las principales leyes de contenido administrativo, que en aquel momento constituyeron el marco jurídico de referencia para la organización y funcionamiento de la Administración estatal.

Como ha recordado Miguel BeLtRÁN VILLALBA ':

- Una reforma de la Administración que se limitase a cambiar, o retocar, las leyes vigentes sería desde luego insuficiente; pero una reforma que las dejase sin tocar adolecería seguramente de igual limitación. Pues bien, el proceso de cambio que se acomete en la Administración española desde la segunda mitad de la década de los cincuenta reformó la legislación, incluso promulgando leyes nuevas que han gozado de una prolongada vigencia, e introdujo, con más o menos éxito, cambios orgánicos y operativos".

Recuperar parte de aquella historia, y hacerlo de una manera sencilla y clara, alejada de la contundencia habitual de la prosa administrativa, puede resultar conveniente para evitar que el pasado más próximo de nuestra Administración llegue a olvi- 
darse. Porque, en definitiva, por alli andan nuestras raíces, los origenes más cercanos de una situación actual que ya casi se presenta como dificil de arreglar. La aparente calma que se extiende por toda la Administración española no es más que el síntoma de la falta de interés (o de imaginación) para emprender de nuevo una reforma administrativa ahora tan pertinente y necesaria como aquélla de los años cincuenta. $O$ del abatimiento que de entrada produce cualquier misión que se presenta como imposible.

Estos estados de ánimo son la causa de la fatiga con que suelen anunciarse cualquier intento cíclico de reforma, cambio o mejora de la Administración, y la poca esperanza con que suele escucharse por parte de los posibles actores o destinatarios de las transformaciones propuestas.

El axioma de la permanencia y continuidad en el tiempo de toda reforma administrativa se ha reducido en la mayoría de los países occidentales a un recurrente tópico en el programa electoral de los principales partidos políticos, que cada vez se incorpora con menos convencimiento en su presentación y más desgana en su realización.

El tema se ha agotado - ¿desacreditado? - tanto durante los últimos veinte anos, que cualquier político que intentara enarbolar de nuevo tan maltrecha bandera con impetus similares a los de los años cincuenta, parecería un anacrónico apóstol que sólo movería a compasión o al sarcasmo.

Por lo que se refiere a nuestro país, puede que no esté de más dar un breve repaso a algunos de los sucesos de la historia más reciente de nuestra Administración, e intentar encontrar en ellos alguna posible explicación del fatalismo y la resignación (incluida la sindical) que ahora nos invade. $\mathrm{O}$, si es posible, alguna pista para salir de ella.

En cualquier caso, la reforma de la Administración podrá seguir siendo una necesidad pero felizmente ya no es una estrategia para frenar planteamientos políticos netamente totalitarios, y menos un instrumento táctico idóneo para acceder al poder. El actual contexto políico, social, cultural y económico de nuestro país no tiene nada que ver con el que nos dominaba en aquellas décadas felizmente superadas.

\section{La necesidad de institucionalizar el régimen de Franco}

La aparición mediados los años cincuenta de un órgano en la Presidencia del Gobierno encargado formalmente de dirigir e impulsar la reforma administrativa del aparato del Estado, no puede sustraerse de la cada vez mayor necesidad de institucionalizar el régimen político español surgido después de la guerra civil.

Institucionalización, por supuesto, de alcance exclusivamente jurídico formal y desde la perspectiva propia de un régimen dictatorial, pero que parecía conveniente y más acuciante desde que terminó el aislamiento internacional del régimen de Franco. Recordemos que si bien en diciembre de 1946 la Asamblea General de Naciones Unidas había recomendado el boicot diplomático al mismo, casi cuatro años más tarde, en agosto de 1950 , anulaba sus anteriores resoluciones, y a partir de febrero de 1951 se iniciaba el regreso de embajadores a Madrid.

En el año 1953 se celebran dos tratados internacionales de innegable relevancia para la consolidación exterior del régimen: el Concordato con la Santa Sede y el Pacto de amistad y cooperación con los Estados Unidos, en agosto y septiembre, respectivamente. Consolidación que se efectúa definitivamente en diciembre de 1955, con el ingreso de España en la O.N.U.

Pero fue un acontecimiento posterior, de ámbito exclusivamente interno, el que resultó determinante para que se iniciara un nuevo intento de institucionalización del régimen, esta vez con una importante fuerza inicial.

Los sucesos estudiantiles de febrero de 1956, a propósito de la celebración de un Congreso Nacional de Estudiantes que relativizaba el protagonismo del oficial Sindicato Español Universitario $y$, por lo tanto, del Movimiento Nacional, alteraron gravemente el orden público en el centro de Madrid. Aquello pareció una nefasta consecuencia de la importante discrepancia política, por no decir enfrentamiento, existente entre dos sectores presentes en el Gobierno: la democracia-cristiana colaboracionista y la Falange. Y que, en definitiva, representaban dos maneras diferentes de entender la evolución del régimen. Franco decretó el cese fulminante de los dos ministros afectados por los hechos y responsables de los mismos, los de Educación Nacional (Joaquín Ruiz Giménez) y del Movimiento (Raimundo Fernández Cuesta) ${ }^{2}$. En sustitución de éste Franco nombró a otro "camisa vieja" de la Falange que ya había sido ministro con anterioridad: José Luis Arrese.

Según Ricardo DE la CieRva ", Arrese llegó a la Secretaría General del Movimiento con el propósito de que la Falange volviera a asumir un papel protagonista, por no decir dominante, en el régimen de Franco. Y ello a través de una doble vía:

uprimero, un incremento del activismo y de la militancia; segundo, un intento de asegurarse el monopolio político en las alturas mediante la confección de unas Leyes Fundamentales totalitarias. 
Pocos clias después del nombramiento de Arrese, el 4 de marzo, se celebra en Valladolid, ciudad emblemática del falangismo, el aniversario de la fusión de F.E. con las J.O.N.S. Acto al que asiste el Ministro y en el que se dirige con un vibrante discurso a los falangistas alli concentrados, a los que enardece y exhorta a "ganar la calle de nuevo si fuese necesario " ${ }^{4}$, al mismo tiempo que reconocía que "la Falange está oscilando entre el aburrimiento de unos y la reacción violenta de otros". Es en este acto donde declara que "tenemos unas leyes fundamentales, pero aún nos quedan otras muchas por hacer ${ }^{5}$. Y siguiendo esta misma línea de actuación se refirió expresamente a la necesidad de hacer otras leyes que articulen la sucesión del poder ejecutivo en la Jefatura del Gobierno y la sucesión del poder político en la Jefatura del Movimiento " ${ }^{6}$.

Arrese pone manos a la obra para lo que contará básicamente con el Instituto de Estudios Políicos y el equipo de catedráticos de Derecho Político y de Teoría del Estado nucleados en torno a esta institución.

\section{Para Ricardo de la Cierva?,}

-su preocupación inicial, junto con el levantamiento de la moral política, muy decaída, del partido, es preparar unas leyes fundamentales que aseguren la preeminencia del partido incluso al margen de Franco; aunque en vida de Franco el partido seguiría identificándose con élo.

El simple anuncio que Arrese había efectuado en Valladolid de la necesidad de preparar unas nuevas Leyes Fundamentales, hace que el Ministro de Justicia, Antonio Iturmendi, perteneciente al sector tradicionalista del régimen, se alerte como teórico responsable y lógico encargado de elaborar la legislación fundamental del régimen. Iturmendi teme que Arrese le haya madrugado los proyectos y se haya entrometido en un asunto que, en principio, debiera ser de la competencia de su Ministerio. Y encarga al catedrático de Derecho Administrativo, Laureano lópez Rodó, un estudio sobre las características que debían reunir las futuras leyes fundamentales que vinieran a completar las anteriores.

Según ha contado el propio López Rodó ${ }^{8}$, en el mes de abril cumple el encargo y entrega al Ministro de Justicia una nota en la que entre otras cosas mantenía que los órganos del Movimiento debían proponer, pero no acordar, la ordenación jurídico-política del régimen. Ésta sería misión de las Cortes. Al mismo tiempo identificaba como posibles temas para las nuevas Leyes Fundamentales los siguientes: a) una ley definitoria de los Principios que informan el Movimiento Nacional; b) un Fuero de la Corona que señalara los deberes y prerrogativas de la institución real, garantizara su independencia y estableciera las limitaciones orgánicas del poder del Rey por las instituciones representativas; c) una Ley Fundamental de la Administración que regulara sus relaciones con el Gobierno y las Cortes; d) un
Fuero de la Justicia; y e) una Ley Orgánica del Consejo Nacional.

Ésta fue, pues, en abril de 1956, la primera aparición formal y directa de López Rodó en el escenario político-institucional de la época, bien es verdad que en una secundaria labor de asesoramiento al Ministro de Justicia. Que consistió en la preparación de una simple nota en la que le exponía su pensamiento sobre la institucionalización del Régimen. Y en la que ya advertía sobre la necesidad de una ley que regulara la Administración del Estado. Pero la táctica de las notas breves, concisas, con la indispensable fundamentación técnica sobre un asunto político determinado, iba a proporcionar buenos resultados a lópez Rodó.

El día 17 de mayo, en una reunión de la Junta Política presidida por Franco, se designa una ponencia encargada de redactar las nuevas Leyes Fundamentales. Por el Gobierno forman parte de la misma el Ministro de Justicia, Antonio Iturmendi Bañales, y el Ministro Subsecretario de la Presidencia del Gobierno, Luis Carrero Blanco. Esta coincidencia de ambos ministros en aquel encargo pudo ser decisiva para la posterior incorporación del profesor López Rodó a la entonces endeble estructura orgánica de la Presidencia del Gobierno, y consiguiente inicio del proceso de reforma administrativa que se inició a mediados de los años cincuenta.

La redacción material de los anteproyectos de Leyes Fundamentales se encomienda al catedrático de Derecho Político y director del Instituto de Estudios Políticos, Javier Conde, que ya en 1941 había publicado su Teoria del Candillaje. En el mes de junio de 1956 se hace llegar a los miembros de la Ponencia el anteproyecto de Ley Fundamental de los Principios del Movimiento Nacional, y en el mes de julio, el de la Ley Orgánica del Movimiento Nacional.

Javier Conde es desplazado a la embajada de España en Filipinas, y el nuevo equipo directivo del Instituto de Estudios Políticos constituido por Emilio Lamo de Espinosa, como director, y Manuel Fraga Iribarne, de subdirector, introducen algunos retoques en los textos ya redactados.

En ambos anteproyectos aparecen pocas innovaciones en el esquema general del régimen político impuesto en España a partir de abril de 1939. Pero las que se introducen son para hacerlo más regresivo respecto de algunos tímidos avances institucionales efectuados en los últimos diecisiete años. $Y$, por supuesto, bien alejado de los sistemas políticos propios de las democracias occidentales vencedoras en la II Guerra mundial. Es como si nada hubiese sucedido en el mundo durante los últimos años. Una vuelta a los principios e ideas que habían inspirado a los regímenes políticos totalitarios de Alemania e Italia en la Europa de los años treinta. 
Así, la idea matriz que subyace en ambos anteproyectos consiste en considerar al Movimiento Nacional, que se entiende fundado por la voluntad del pueblo español, legítimamente expresada en el Glorioso Alzamiento (sic), como organización intermedia entre la Sociedad y el Estado, a la que, como superior entidad política, le corresponde, de modo prescriptivo y permanente, representar y actualizar la voluntad política de los espanòles.

$\mathrm{Ni}$ que decir tiene que el articulado de los anteproyectos tiende a desarrollar y hacer efectiva esta idea básica, de inequívoca ideología totalitaria, llegándose al extremo de someter el Gobierno al control y tutela del Consejo Nacional y, a través de él, al de la propia Secretaría General del Movimiento.

En esta misma línea, otro exceso importante que contenían los textos preparados por el Instituto de Estudios Políticos fue la preeminencia que se daba al Ministro Secretario General del Movimiento en todo lo relativo a la sucesión en la Jefatura del Gobierno, llegándole a situar en un plano de igualdad con el Presidente de las Cortes. Pero lo más llamativo, por su atrevimiento e ignorancia de otros textos fundamentales aprobados en 1942 (Ley de Cortes) y 1947 (Ley de Sucesión en la Jefatura del Estado), fue la omisión expresa de cualquier referencia a la Monarquía o mención a la figura del Rey como futuro Jefe de Estado.

Los regímenes democráticos occidentales tampoco salian muy bien parados. En el anteproyecto de Ley que definía los Principios del Movimiento Nacional se llegaba a afurmar que el sistema de partidos políticos con todas sus consecuencias, sufragio inorgánico, representación por bandos en lucha e instituciones de concurrencia parlamentaria, se entiende definitivamente abolido.

¿Qué razón pudo impulsar a Arrese para patrocinar unos textos tan extravagantes y contradictorios con otras Leyes Fundamentales anteriores, al pretender la vuelta en mitad de la década de los cincuenta a un modelo de régimen político ya completamente olvidado en Europa occidental?

Stanley PAYNE aventura la siguiente interpretación:

-Arrese esperaba que una doctrina neofalangista desfascistizada, aun cuando fuera totalmente repudiada por Europa occidental, podría ejercer todavía influencia en Oriente Medio, en los Estados árabes con los cuales el régimen español mantenía relaciones cordiales ${ }^{*}$.

Las reacciones no se hicieron esperar. Tanto Iturmendi como Carrero enviaron sendas notas oponiéndose radicalmente al contenido de los anteproyectos que se habían redactado con vistas a su discusión en la Ponencia. El primero había encargado de nuevo a López Rodó otras notas; una general, sobre los
Principios Fundamentales del Estado, y otra especifica, referida a los proyectos concretos de Arrese.

Pero el golpe de gracia a los textos elaborados estuvo a cargo tanto del Presidente de las Cortes Españolas como de los máximos representantes de la Iglesia Católica de nuestro país.

El primero, Esteban Bilbao y Eguía, uno de los principales representantes del tradicionalismo integrado en el Movimiento, en una extensa carta de once folios dirigida a Arrese ${ }^{10}$ mostraba su radical disconformidad con los proyectos que éste había preparado. $Y$, al final, se despedia de la siguiente manera:

- $Y$ con estos anteproyectos, Arrese amigo, no se gana la calle, ni se gana el Estado, ni se conquista el pueblo. España, que vistió largos años el manto imperial, que hoy adorna su escudo, no lo cambiará jamás por una camisa de fuerza: eso es posible en Rusia, país acostumbrado a la servidumbre, pero no duraria una semana en España, pueblo acostumbrado a la libertad, enamorado de la justicia y celoso de su dig. nidad.

Amigo Arrese, si usted me permite un consejo fruto de mi ya larga experiencia, abandone esos proyectos que en lugar de unirnos nos dividen y dificultan la solución.

Al margen de la retórica propia del régimen y del personaje, la carta de Esteban Bilbao no dejaba dudas sobre su posición contraria a las propuestas del Ministro Secretario General del Movimiento.

Algo similar sucedió con la entrevista que el 12 de diciembre mantuvo Franco con los tres cardenales españoles (Quiroga Palacios, Arriba y Castro y Pla y Deniel), en la que éstos llegaron a decirle que conocian muchas personas que estando dispuestas a dar su vida por España y por el Jefe del Estado, también lo estarian por alzarse por todos los medios a su alcance contra unos proyectos que contradecían los principios del Derecho Público cristiano y el sentir católico del pueblo español ". En un documento que le entregaron llegaban a identificar la forma de Gobiemo proyectada para España en los textos distribuidos, con una dictadura de partido único "como fue el fascismo en Italia, el nacional-socialismo en Alemania o el peronismo en la República Argentina, sistemas que dieron mucho que deplorar a la lglesia.

CAlvo SeRER ha descrito acertadamente ${ }^{12}$ cuál debió ser, en sintesis, la reacción final ante estos propósitos de institucionalización provenientes del sector falangista del régimen:

- Contra Arrese, se movieron los monárquicos, los militares, los demócratas cristianos colaboracionistas y los cardenales españoles. Ante tal oposición Franco desautorizó a Arrese y todo quedó, en enero de 1957, como estaba antes del ruido promovido alrededor de este asunto, pese a subsistir una 
opinión muy extendida favorable a la institucionalización del régimen franquista".

De todos estos acontecimientos políticos ocurridos durante los primeros meses de 1956 López Rodó estuvo al corriente a través de una fuente privilegiada: la del propio Ministro de Justicia, Antonio Iturmendi. Pero es más, había tenido incluso la oportunidad de exponer sus ideas y opinión sobre la institucionalización del régimen en las notas que el mismo Ministro le habia encargado.

López Rodó tenía, pues, una información de primera mano acerca de los intentos de la Falange para afianzarse institucionalmente dentro del régimen de Franco y de los propósitos de futuro para cuando éste desapareciera, entre los que no figuraba una nueva restauración monárquica. Así como de las reacciones contrarias que habían provocado por parte de otros sectores políticos también integrados en el Movimiento o simplemente fieles a Franco. Tampoco desconocía la crisis de Gobierno latente desde hacía tiempo, y que se había resuelto, sólo en parte y provisionalmente, en febrero, con el cambio de dos ministros.

\section{Recuerda Stanley PAYNE que}

- desde el verano anterior se hablaba de una cambio general del Gobierno, y Arrese venía trabajando en una expansión de la influencia falangista en el gabinete 1.

Por otra parte, el perspicaz profesor de Derecho Administrativo debía saber que los cambios ministeriales más importantes del régimen siempre habían estado acompanados de importantes reformas en la estructura de la Administración del Estado. Así había ocurrido en 1939, después de terminar la guerra civil, y también en 1945, al finalizar la II Guerra mundial. Pero sobre todo en julio de 1951, cuando se elevó a rango de Ministro al Subsecretario de la Presidencia del Gobierno, y se creó el Ministerio de Información y Turismo, entre otras novedades organizativas.

Es decir, López Rodó sumaba a unos razonables conocimientos técnicos sobre la materia, una visión muy precisa del momento político por el que atravesaba el régimen. No hacía falta ser un avezado analista político para percibir, como dice Javier TUSELL ${ }^{14}$, que los esquemas institucionales de Arrese

"no sólo no eran aceptables --[para Carrero]-, sino que pertenecían a otra galaxia, pero el hecho de que hubieran sido planteados implicaba la necesidad de que se pensara en otros distintos.

Esto es precisamente lo que hizo López Rodó. Sacar el mejor provecho político de la privilegiada información que había obtenido a través de Iturmendi en relación con los propósitos institucionalizadores del régimen por parte de Arrese. Y cuando fue consultado, primero por aquél y, más tarde por Carrero, como veremos a continuación, se encontraba en inmejorables condiciones para ofrecer una alternativa que supusiera no insistir por el momento en los planteamientos exclusivamente de política institucional que el Ministro Secretario General del Movimiento había radicalizado, produciendo desasosiego e irritación en otros sectores del régimen.

No es que López Rodó fuera un oportunista. Sencillamente sabía que su baza consistía en ofrecer una alternativa reformista que, sin provocar de entrada las tensiones derivadas de cualquier intento de institucionalizar ( $y$, por lo tanto, cuestionar) todo el poder otorgado al Jefe del Estado en octubre de 1936, permitiera avanzar al menos retóricamente en el perfeccionamiento del régimen. Aunque fuera en su faceta menos trascendental desde una perspectiva estrictamente política: la de la reforma de la Administración. Pero de más fácil planteamiento. Y es lo que precisamente hizo.

La mejor opción que quedaba consistía en presentar una vía técnica de reforma, sencilla y eficaz, para mejorar la organización y el funcionamiento de la Administración del Estado, a la vista de los nuevos cometidos y actividades que el sector público había ido asumiendo durante los últimos años. No olvidemos que aquella continuaba rigiéndose por dos leyes promulgadas por Franco en solitario: las de 30 de enero de 1938 y 8 de agosto de 1939. Y lo que estaba fuera de toda duda es que quienes dirigían en aquella época el Movimiento no se encontraban capacitados por muy diversas mazones (desde las meramente profesionales hasta su concepción sectaria y militante de la adhesión inquebrantable e ideológicamente interesada, primero, a la Falange, y después, a Franco), para llevar a cabo una operación de esta envergadura. Que, entre otras cosas, podía desembocar en el principio del fin del mismo Movimiento Nacional. Se trataba de personas más preparadas y propicias para cantar a los luceros y dar los gritos de ritual que para hablar de la organización administrativa o de magnitudes macroeconómicas.

De todas formas, no convendría olvidar que las notas iniciales que López Rodó entregó a Iturmendi en los primeros meses de 1956, se referían sólo a cuestiones genéricas relacionadas con los principios inspiradores del Movimiento Nacional, al ordenamiento complementario de las Leyes Fundamentales promulgadas hasta el momento, y a los proyectos concretos de Arrese. Entre los que es cierto que figuraba un anteproyecto de Ley de Ordenación del Gobierno. Pero que poco o nada tenían que ver con una reforma puramente técnica de la Administración del Estado, concebida en principio como una simple mejora o perfeccionamiento de la actividad administrativa.

Las aspiraciones de Arrese - no ofrecían duda- eran más elevadas, de más altos vuelos. Se trataba ni más ni menos de que la Falange, con la pantalla del Movimiento, fuera poco a poco dominando todos los mecanismos del poder del Estado español, reunidos desde 1936 en la persona del general Franco. 
Los planteamientos que hizo López Rodó en noviembre de 1956 fueron inicialmente más modestos que los de Arrese, aunque sólo lo fuesen a corto plazo o sirvieran de camuflaje para otros propósitos también institucionales de mayor envergadura y signo. Lo que no cabe discutir es el mérito que tuvo de llanar la atención sobre algo que hasta ese momento nadie había patrocinado con insistencia: que hoy por hoy podría ser suficiente con una reforma administrativa. Reforma que, entre otras cuestiones, también podía llevar aparejada una nueva ordenación de la organización ministerial que facilitara al mismo tiempo la aplazada crisis de Gobierno. Éste fue el principal mérito de López Rodó. Como opina Ricardo dE LA CIERva ${ }^{15}$ :

-López Rodó ya estaba precalentándose en la banda durante estos meses convulsos e inciertos de 1956 .

\section{La corta marcha de López Rodó hacia la política}

El principal inspirador del Decreto-Ley de 20 de diciembre de 1956, por el que se crea la Secretaría General Técnica de la Presidencia del Gobierno, Laureano LOPEZ RODO, ha comentado en sus Memorias ${ }^{16}$ que

-mientras que la ponencia, en abierta disconformidad con Carrero e Iturmendi, proseguía sus trabajos de redacción de los anteproyectos de Leyes Fundamentales, tuvieron lugar dos hechos aparentemente irrelevantes -la celebración en Madrid de un Congreso de Ciencias Administrativas y mi conferencia de clausura del Curso Universitario de Verano de Santiago de Compostela- que, sin que yo pudiera imaginarlo, me introducirían en la política activa.

Efectivamente, en septiembre de 1956 tuvieron lugar ambos acontecimientos, con una semana de diferencia, en Madrid y en Santiago de Compostela.

Durante los primeros días de septiembre, del 3 al 8 , se celebró el X Congreso Internacional de Ciencias Administrativas en la sede del Consejo Superior de Investigaciones Científicas, organismo del que López Rodó era Secretario Técnico desde 1952. El Congreso había sido organizado por la Sección española del Instituto Internacional de Ciencias Administrativas, que presidia José Gascón y Marín ${ }^{17}$, ex Ministro de Instrucción Pública y Bellas Artes de la Corona y catedrático jubilado de Derecho Administrativo, tronco académico común y próximo (por no decir único) de todos los jóvenes administrativistas españoles ${ }^{18}$. Gascón y Marín encargó a López Rodó la secretaría del
Congreso, uno de cuyos temas principales era, precisamente, el de los procedimientos para la preparación y realización de las reformas administrativas ${ }^{19}$.

\section{a) Una coincidencia afortunada: la conferencia de López Rodó en Santiago y el final del veraneo oficial en Meirás}

\author{
Cuenta LOPEZ RODÓ ${ }^{20}$,
}

- Esta circunstancia me llevó a elegir el mismo tema para la conferencia de clausura del VIII Curso Internacional de Verano de Santiago de Compostela, que tuvo lugar el 15 de septiembre bajo la presidencia del Ministro de Educación, Jesús Rubio - fque había sustituido a Joaquín Ruiz Giménez en la crisis del pasado mes de febrerol-, y con asistencia del Director General de Enseñanza Universitaria, Torcuato Fernández Miranda, y del Secretario General Técnico del Ministerio de Educación, Antonio Tena.

Esto fue el 15 de septiembre. Al día siguiente se celebra Consejo de Ministros en el Pazo de Meirás, cerca de la Corıña, presidido por Franco. El Ministro de Educación comenta elogiosamente el contenido de la conferencia pronunciada el día anterior por López Rodó. Con posterioridad el Ministro de Justicia le pide el texto de la conferencia,

-...porque le interesaba leerlo y quería entregárselo al Jefe del Estado. Así lo hizo. A Franco le pareció bien la reforma que yo propugnaba y ordenó al Ministro Subsecretario de la Presidencia, Carrero, que me pidiera una nota sobre la manera de llevarla a cabo ${ }^{21}$.

¿Qué había dicho López Rodó en su conferencia? El texto fue publicado en el número 27 de la revista Nuestro Tiempo, del mismo mes de septiembre de 1956, con el título -La reforma administrativa del Estado, y está escrito en un lenguaje claro y fácilmente comprensible, directo, exento de tecnicismos esotéricos, aunque con alguna que otra breve concesión a un sorprendente lirismo populista ${ }^{22}$.

Se puede decir que en su breve parte introductoria recoge todos los mejores tópicos doctrinales del momento (cambio acelerado en la vida moderna; la Administración conformadora del orden social; nuevas necesidades colectivas; exigencia de eficacia de la Administración para satisfacerlas...). E inmediatamente entra de lleno en los aspectos estratégicos de la reforma: enfoque y objetivos.

Descalifica las reformas propugnadas desde posiciones liberales ("no podemos compartir la postura cómoda de aquéllos para quienes la mejor Administración es la que menos les molesta...) o de los que se limitan a su identificación interesada con la reducción de los impuestos (....y menos les cobra.), para terminar enunciando lo que llegaría a ser la constante melodía 
de fondo de todo el proceso ulterior de reforma; es decir, se trata de una serie de medidas concretas para dar mayor agilidad y eficacia a la Administración. La agilidad con diversas manifestaciones y la eficacia como valor supremo fueron principios expuestos hasta la saciedad en normas, discursos, conferencias y estudios. De tal manera que se convirtieron en los dogmas permanentes e incuestionables de aquel movimiento de reforma, que a veces llegó a predicarse con fervor casi religioso.

Y a partir de ese momento López Rodó expuso en su conferencia un conjunto de principios y acciones tendentes a tal fin, aunque - como advierte - "no pretendo formular una programa de reforma de la Administración. Sino exponer tan sólo las directrices dominantes en el plano de la ciencia administrativa. Aclaración modesta pero un tanto discutible, máxime cuando la esencia de lo expuesto en esta conferencia se convirtió a los tres meses en el contenido material del Decreto-Ley de 20 de diciembre de 1956 que creó el órgano administrativo que facilitó su acceso a la Presidencia del Gobierno dirigida por el almirante Carrero Blanco.

López Rodó llegó a enunciar un conjunto de actuaciones para cada uno de los tres aspectos en que consideraba que se había de desarrollar la reforma: la organización, el funcionamiento y el personal de la Administración pública. De esta manera, la reforma administrativa se desagregaba, de entrada y en un plano teórico, en una triple reforma: reforma orgánica, reforma luncional y reforma burocrática. Esta clasificación enseguida adquirió carta de naturaleza y con posterioridad se convirtió en el esquema básico para el seguimiento y evaluación de las acciones que se desarrollaron.

En materia de reforma orgánica López Rodó destaca la necesidad de la desconcentración de funciones, más importante y más urgente que la descentralización, para evitar el colapso de la vida administrativa. Para ello propugna la creación de Comisiones permanentes de Ministros para dotar de mayor agilidad a la estructura del Gobierno, como sucede en Italia, Holanda, Portugal y Francia. También apunta la necesidad de revisar la división ministerial para atender a los problemas más importantes, refiriéndose expresamente al de la vivienda ${ }^{23}$. Al mismo tiempo recuerda que en algunos paises europeos (Francia, por ejemplo) el número y denominación de los Ministerios varía en cada crisis ministerial. Pero donde pone énfasis es en la necesidad de contar con unos órganos específicos de coordinación que aseguren la unidad de la acción gubernativa y eviten interferencias y duplicidades. Y, sobre todo, la dispersión de esfuerzos. En este orden de cosas llega a advertir:

-La coordinación viene a ser la contrapartida de la desconcentración. Sin la desconcentración la máquina administrativa no marcha; sin coordinación, se moverá descompasadamente.
Y después de efectuar un breve y oportuno excurrus sobre la división y enemistad entre los ministros, llegando a citar a Bodino, Maquiavelo y al Padre Márquez, propugna la creación de un órgano central de coordinación, citando los casos de Italia, Portugal y Francia, países en los que ya se habían creado en las proximidades de la Presidencia o de la Secretaría General del Cobierno.

Es verdad que cuando se trata de dotar de funciones a este nuevo órgano central, López Rodó llega a sobrepasar lo que podría ser el estudio de los métodos de trabajo, de organización administrativa y de los funcionarios públicos, para extender su posible ámbito de actuación a la preparación de los presupuestos $^{2: 4}$, la elaboración y coordinación de los programas económicos y la coordinación de las obras públicas. Si bien al final matiza el papel de este nuevo órgano e intenta tranquilizar ante la posible alarma de un planteamiento tan ambicioso:

-Su misión consiste más bien en cooperar con los distintos Ministerios, obtener datos e información de los mismos, estimular, coordinar y asesorar. De aquí que no merme ni modifique en absoluto la competencia de los ministros, ni se injiera para nada en los asuntos que les son privativos".

De la lectura actual de la conferencia de lópez Rodó se puede advertir que, en cambio, no tenía las ideas tan firmes en materia de reforma funcional, pues de entrada se limita a afirmar que de la reforma orgánica -se obtendrá indirectamente un mejoramiento funcional, es decir, una mayor eficacia y celeridad en la acción administrativa. A pesar de esta afirmación, a continuación se refiere brevemente a reformas directas encaminadas a modernizar los métodos de trabajo, como son la aplicación de la mecanización, la cibernética, la psicología industrial o las relaciones humanas. Todo un poco revuelto.

Tras reproducir íntegramente las conclusiones del Congreso de Profesores de Derecho Administrativo y disciplinas relativas a la organización de empresas, celebrado hacía un año en Varenna, a propósito de las técnicas empresariales que puedan ser aplicadas en la Administración pública, lo que resulta un poco forzado en el contexto del discurso, hace una breve incursión en lo referente al procedimiento administrativo. Llama la atención sobre la inexistencia de una regulación jurídica del silencio administrativo, afenómeno - dice- por desgracia frecuente. Y sugiere que al revisarse las normas del procedimiento administrativo debería simplificarse la tramitación de los expedientes, abreviar los plazos y reducir el papeleo , citando medidas adoptadas en Francia e Italia para la simplificación de las formalidades administrativas y para dar las máximas facilidades a los administrados en su relaciones con la Administración.

Por último, la reforma burocrática. Es la reforma a la que López Rodó dedicó menos espacio. Prácticamente se limitó a poner énfasis en la formación permanente de los funcionarios, 
que conecta a la necesaria obtención de algún beneficio ("especialmente económicon), y por ello la enlaza con el ascenso. Distingue el sistema automático de la antigüiedad para el aumento del sueldo, del acceso a los cargos superiores que debe depender únicamente del mérito. Para ello también hace un breve comentario sobre la valoración o calificación del personal con vistas al ascenso, como sucede en los modernos Estatutos de funcionarios de Francia e Italia.

En la última parte de la conferencia efectúa una extensa referencia a los órganos específicamente encargados de la reforma administrativa; lo que él llama instrumentos para preparar la reforma. Y aquí distingue entre los órganos de estudio y los de ejecución ${ }^{25}$.

Después de enunciar un conjunto de medios utilizados en otros países (entre los que sorprendentemente se refiere a las comisiones parlamentarias y a las de encuesta), se decanta por el nombramiento de una Comisión, haciendo unas consideraciones sobre los pros y los contras de determinadas composiciones (funcionarios, técnicos ajenos a la Administración, especialistas de Derecho Administrativo, particulares como destinatarios de los servicios públicos...). López Rodó no se muestra partidario de una opción determinada. Sencillamente se limitó a describir, una vez más, los ejemplos que ofrecen las experiencias de otros paises, pero lo hace de una forma bastante deslavazada. Donde parece que López Rodó tiene una posición más firme es en la necesidad de contar con órganos ejecutivos de las reformas, como ha sucedido en Dinamarca, en Francia y en Italia. En relación con este último país dice:

-Es donde la reforma ha adquirido un mayor impulso... y se ha llegado al nombramiento de una Ministro para Reforma Administrativa que en unos meses ha dictado 67 disposiciones generales de reforma, algunas tan fundamentales como el nuevo Estatuto de funcionarios, las que crean el Consejo Superior de la Administración y la Escuela Superior de la Administración, la de descentralización administrativa, que confiere a las corporaciones locales, más próximas a los interesados, gran número de atribuciones que antes correspondian a la Administración Central.....

Termina la conferencia con un endoso, sutil pero directo, de la cuestión al nivel político. No olvidemos que preside el acto Jesús Rubio, Ministro de Educación Nacional. Pues bien, López Rodó le recuerda sus propias palabras en el discurso inaugural del recién celebrado Congreso Internacional de Ciencias Administrativas: dos esquemas administrativos - a diferencia de los políticos— son fácilmente intercambiables". Oportunas y convenientes palabras en boca de un Ministro de Franco. De ahi que el recuerdo de la frase por el conferenciante fuese muy pertinente. López Rodó desarrolló la idea del Ministro de la siguiente manera:
"La tarea técnica o administrativa podemos considerarla muy avanzada, por ser patrimonio de todos los países... Ahora falta que el poder político realice simplemente un acto de voluntad. Siempre ha ocurrido así. Todas las grandes reformas administrativas se han realizado a la sombra de una gran figura política. Y la labor administrativa ha sido la que ha perdurado, a través de los cambios políticos posteriores.

Y citó a continuación con gran desenvoltura no exenta de audacia, a Richelieu, Colbert y al propio Napoleón, para concluir diciendo:

«Nada queda hoy del imperio napoleónico, pero ahí están todavía los Prefectos y el Consejo de Estado dando testimonio vivo y actual de su paso por la historia de Francia.

No es de extrañar que la conferencia encantara al Ministro de Educación Nacional y que se apresurara a comentarla el día siguiente en la reunión del Consejo de Ministros. Y que de ahí surgiera el inmediato interés del Ministro de Justicia y más tarde del propio Jefe del Estado, que después encargó a Carrero Blanco que pidiera una nota al conferenciante sobre la manera de llevar a cabo la reforma administrativa.

Qué duda cabe que la conferencia carecía en determinados pasajes de precisión técnica, presentaba importantes lagunas en algunos aspectos y exageraba otros (como el relativo al silencio administrativo). También se podrá decir que fue superficial o poco riguroso en muchas de las cuestiones que abordó. Pero no se puede negar que estaba bien estructurada, ordenada sistemáticamente y con abundantes referencias a la doctrina o al Derecho comparado. Aunque algunas pudieran resultar exóticas, como las relativas a Colombia y a su contralor general -el señor Ruiz Novoa-, a Dinamarca, o a un estudio de Ralph Burton publicado por la Administración de Asistencia Técnica de Naciones Unidas. Lo que no oscurecía los oportunos ejemplos sobre la Administración cotidiana y las precisas referencias a los entonces llamados particulares. Pero su mérito indiscutible es que utilizó un lenguaje nuevo para hablar de la Administración, sencillo y atractivo, exento de complicados tecnicismos jurídicos. Lo que le permitió ser eficaz; es decir, alcanzar el objetivo que se había propuesto: que el Gobierno tuviera noticia de las reformas administrativas que se habían emprendido en otros países. Y así fue; el tema llegó enseguida hasta la mesa del Consejo de Ministros y Franco se interesó por él.

López Rodó, por otra parte, fue muy hábil en el planteamiento de la conferencia. Eludió cualquier referencia a la reforma política de alto fuste que se pretendía realizar desde la Secretaría General del Movimiento, y que ya había empezado a fracasar estrepitosamente. Evitó presentarse como un taumaturgo dispuesto con su varita mágica a transformar la Administración. Sencillamente apuntó a grandes rasgos, puede que de manera un tanto vaga y caprichosa, cómo habían solucionado 
otras Administraciones algunos de los problemas derivados de su organización y funcionamiento ante las nuevas demandas de la sociedad. Pero sin dejar de arrimar el ascua a su sardina como hizo, por ejemplo, cuando presentó las ventajas del órgano central de coordinación para remediar las divisiones y enemistades entre los ministros ${ }^{26}$, incluyendo algunas citas muy eruditas en apoyo de su tesis. O al final, al mostrar el espejuelo de la gloria histórica que podría derivarse del hecho de impulsar la reforma de la Administración española. Lo que, sin duda, podía ser un buen cebo para espíritus vanidosos o sencillamente convencidos de haber sido elegidos por la Providencia para salvar a España.

\section{b) Una nota de relevancia fundamental}

La siguiente nota que elabora López Rodó sobre esta cuestión ya es mucho más concreta y se centra en lo que habría que hacer en España. Se trata de un breve documento de sólo tres páginas mecanografiadas a doble espacio, y que lleva por título "Nota sobre la reforma administrativa." ${ }^{27}$.

Se inicia con el tópico de la constante aparición de nuevas necesidades sociales, lo que ureclama de la Administración Pública -instrumento ejecutivo de la política del Gobierno- una mayor eficacian, y de la dificultad de respuesta por parte de una Administración sujeta a nomas decimonónicas, uplasmada en gran parte con arreglo a los moldes de Estado liberal. Lo que además de ser cierto tenía el valor añadido de recordárselo a las principales autoridades de un régimen que no se caracterizaba por su entusiasmo y adhesión hacia aquel modelo. Arremeter contra el liberalismo era entonces la mejor garantía de ser escuchado.

$\Lambda$ continuación incide en los tres campos sobre los que debe proyectarse la reforma administrativa, siguiendo la idea ya expuesta con anterioridad en su conferencia: el orgánico, el funcional y el del personal (en vez de burocrático, aunque más adelante, en el mismo documento, se vuelve a usar esta expresión).

En el primero, se refiere a la descentralización a favor de las Corporaciones locales y otros organismos autónomos, amás próximos a los interesados", y a la desconcentración para "resolver los asuntos con la debida atención y rapidez. Y como contrapartida a ambas, tal y como ya había anticipado en la conferencia, da entrada al principio de coordinación.

Aquí ya se decanta expresamente por la creación de una Secretaría General Técnica en la Presidencia del Gobierno, dado que a ésta le compete tradicionalmente la acción coordinadora. - Este órgano existe ya en gran número de Ministerios ${ }^{28}$ pero no en la Presidencia, que es donde su necesidad sube de punto, y ha dado excelentes resultados como instrumento de coordinación.
A continuación hace un excursis sobre la coordinación administrativa como fenómeno común a todos los Estados modernos, citando expresamente los casos de Portugal ("cuyo régimen administrativo es muy afín al nuestro.) y Francia (aque ha tenido siempre malos gobiernos, no se ha hundido en el caos porque tiene buena Administración.).

A la Secretaria General Técnica propuesta -sigue planteando López Rodó-, además de la coordinación administrativa se le podría encargar la reforma administrativa, ya que tha de encomendarse a un órgano ejecutivo eficaz y no a una comisión, útil para asesoramiento pero nunca como instrumento de trabajo y de ejecución.

Los dos aspectos restantes, la reforma funcional y la de personal, los despacha en sólo tres párrafos. La reforma funcional "consiste en la revisión del procedimiento administrativo", indicando para ello unos criterios tan razonables como simples: - simplificar la tramitación de los expedientes, abreviar y unificar los plazos y eliminar las formalidades inútiles. También esta reforma debe abarcar otra revisión: la de la Ley de Administración y Contabilidad del Estado, como fuente de una efrondosa y anticuada legislación relativa a las obras públicas y a las construcciones civiles". Y por último, "la revisión del actual Estatuto de Funcionarios de 1918 que ha sido objeto de derogaciones parciales por su inadaptación a las circunstancias presentes.

López Rodó concluye su programa inicial de la reforma del personal con una síntesis de las principales acciones que deberian emprenderse en esta materia: ·Han de renovarse los métodos de selección y formación de los funcionarios, las condiciones de ascenso, el control de su eficacia y rendimiento para que el Estado y los intereses públicos cuenten con los mejores servidores.

Y no hay más. En definitiva, la propuesta que se contiene en esta nota de cómo llevar a cabo la reforma administrativa consistió básicamente en la creación de una Secretaría General Técnica en la Presidencia del Gobierno, no sólo como órgano de coordinación central sino también encargado, en cuanto órgano ejecutivo, de la revisión de las Leyes de Procedimiento Administrativo, de Administración y Contabilidad y, por último, del Estatuto de Funcionarios.

Por lo tanto, López Rodó opta en la nota por un órgano con una doble misión. Una inmediata, encaminada a coordinar la actuación de los Ministerios; y la más remota, consistente en la preparación de las nuevas leyes que establecieran una nueva ordenación de la actividad y los medios personales de la Administración del Estado.

No cabe pasar por alto la finura política que ya mostraba López Rodó en aquella nota de noviembre de 1956, para empezar a alcanzar espacios de poder en el ámbito de la Administración. Era más propia de un estratega que de un científico. El 
modelo de nuevo órgano encargado de la reforma que patrocinaba era, desde el plano teórico o conceptual, bastante discutible. Un órgano que reuniera al mismo tiempo funciones de estudio con otras de coordinación, y sobre todo a nivel interministerial con un simple rango de dirección general, era dificil de entender. Pero estaba bien pensado a efectos de ir alcanzando, poco a poco, las zonas de mayor influencia dentro de la Admiristración.

Por un lado, tener acceso y participar en la actividad diaria de los Ministerios con el pretexto de la coordinación. Por otro, diseñar una futura organización y funcionamiento de la Adninistración a través de nuevas leyes que permitieran la consolidación del papel coordinador de la Presidencia del Cobierno. No era mala estrategia.

En el Decreto-Ley de 20 de diciembre de 1956 todavía no aparece explicitada la función coordinadora de la Secretaría General Técnica, lo que se consiguió más tarde, en el de 25 de febrero de 1957. En cambio, se le encomendó desde el primer momento la actividad de preparar las nuevas leyes de reforma y perfeccionamiento de la organización y actividad administrativas. $Y$ en este aspecto puede afirmarse que, salvo lo relativo a la actualización de las normas de Administración y Contabilidad (o lo que era lo mismo, una nueva legislación en materia presupuestaria, de contratación administrativa y de patrimonio del Estado), cuyo protagonismo no estaba dispuesto a ceder el Ministerio de Hacienda, se alcanzaron todos los objetivos expuestos por López Rodó en aquella escueta nota.

A finales de 1958 (plazo espectacular por breve), ya se habian promulgado cuatro leyes de innegable repercusión para el propósito ordenador de una nueva Administración: la de Régimen Jurídico de la Administración del Estado, de Procedimiento Administrativo, y las de Entidades Estatales Autónomas y de Tasas y Exacciones Parafiscales. Bien es verdad que estas dos últimas, patrocinadas e impulsadas por el Ministerio de Hacienda. En cambio, la reforma legal de la Función Pública tardó un poco más; hubo que esperar hasta julio de 1963.

\section{Preparación y antecedentes del Decreto-Ley de 20 de diciembre de 1956}

Carrero Blanco, después de despachar el asunto con el Jefe del Estado, encarga ahora directamente a López Rodó la redacción de un borrador de decreto-ley para crear la Secretaría General Técnica ${ }^{29}$.
En primer lugar, puede resultar chocante desde una perspectiva actual el elevado rango formal que se dio a la disposición. Entonces no existía régimen jurídico alguno aplicable con carácter general a la creación de direcciones generales, y ejemplos había para todos los gustos, desde la ley a la mera orden ministerial. Pero acudir a la vía del decreto-ley tenía varias lecturas. Y la no menos importante era que con este rango quedaba claro que se trataba de una decisión personal de Franco, que él asumía directamente.

No se trataba, pues, de una iniciativa de algún ministro (en este caso, Carrero) que posteriormente fuera validada por el Consejo de Ministros a través del correspondiente decreto. La creación de la Secretaría General Técnica de la Presidencia del Gobierno y los cometidos que iba a desempenar contaban, de entrada, con apoyo al más alto nivel político. Significaba, ni más ni menos, que la idea de la reforma administrativa había sido asumida personal y directamente por el propio Jefe del Estado. Y un aval de este nivel político en cualquier caso, pero más en aquella época, tenía su innegable trascendencia.

El rango formal suponía además que la decisión no pasaría desapercibida. Lo que coircidía con los propósitos de lópez Rodó, ya que tampoco pretendía entrar de puntillas en la Administración.

\section{a) Los borradores iniciales}

El contenido del primer borrador de decreto-ley del que se ha podido disponer (sin fecha) ${ }^{30}$ en poco difiere del que apareció en el Boletín Oficial del Estado del día 22 de diciembre.

De todas formas se introdujeron algunas modificaciones como consecuencia de las observaciones enviadas por algunos Ministros, a las que más adelante nos referiremos, y por el Oficial Mayor de la Presidencia del Gobierno, Ricardo Ruiz Benítez de Lugo y Ruiz ${ }^{31}$.

La exposición de motivos era prácticamente una reiteración, casi literal en algunos párrafos, de lo expuesto en la nota inicial de López Rodó. Pero del primer borrador se suprimieron dos párrafos. Precisamente en uno de ellos, que aparecía en el tercer lugar, se hacia referencia a la necesidad urgente de simplificar la tramitación de los expedientes, abreviar y unificar los plazos y eliminar formalidades inútiles, interferencias y duplicidades. Y también, aunque muy genéricamente, a la descentralización de servicios, desconcentración de funciones, la coordinación por supuesto, y la reforma burocrática en lo concerniente a la renovación de los métodos de selección y formación de los funcionarios y el incremento de su rendimiento. El otro párrafo desaparecido, situado en quinto lugar, hacía referencia a la acción coordinadora de la Administración General del Estado que compete a la Presidencia del Gobierno, y a la 
creación de un órgano específico de carácter técnico al que se encomienda el estudio, planeamiento y ejecución de la reforma administrativa en su triple aspecto orgánico, funcional y burocrático.

Este párrafo en cierta manera insistía en la misma idea expuesta en el siguiente, que permaneció sin modificación alguna y así fue definitivamente aprobado. En él se explica la creación de una Secretaría Ceneral Técnica, similar a las ya existentes en otros Ministerios, para realizar funciones de estudio, documentación asistencia técnica y elaboración de planes concernientes al perfeccionamiento de la Administración General del Estado que permitan, con criterio de unidad, la necesaria reforma administrativan.

(Un breve paréntesis para resaltar un dato curioso: en el preámbulo del Decreto-Ley se utilizó la expresión «Administración General del Estado", poco usual en aquella época, y que cuarenta años más tarde, en abril de 1997, sirvió para titular la Ley que establecía su Organización y Funcionamiento: la LOFAGE).

Como ya se ha dicho, en cuanto al contenido material, pocas diferencias existen entre las versiones iniciales del decreto-ley y la que definitivamente fue aprobada. Sin embargo, convendría recoger dos de mayor entidad.

En uno de los primeros borradores aparece la constitución de un Consejo de Reforma Administrativa afecto (sic) a la Secretaria General Técnica, cuyos vocales serán nombrados por el Ministro Subsecretario, a propuesta del Secretario General Técnico, para la preparación y estudio de las medidas que hayan de adoptarse con objeto de mejorar la eficacia de la Administración. Idea que no prosperó. Y que en sucesivas versiones fue reemplazada por la facultad atribuida al Ministro Subsecretario para que, a propuesta del Secretario General Técnico, pudiera -interesar (sic) la incorporación a la referida Secretaría General T"écnica de funcionarios de cualesquiera de los Cuerpos de la Administración General del Estado, para los cuales será de aplicación lo previsto en el apartado b) del artículo 4 de la Ley de 15 de julio de $1954{ }^{32}$. Este precepto permitía a los funcionarios, con autorización de su respectivo Ministro, prestar servicio en otro Departamento en concepto de agregados.

Sin cluda alguna hubo de plantearse la recurrente dialéctica entre funcionarios o "personas de la calle, para formar el equipo del órgano de nueva creación. Y se optó formalmente por los Cuerpos de funcionarios como fuente normal de reclutamiento del personal de la nueva Secretaría General Técnica. Y ello, como se decía en el propio Decreto-Ley, "a los fines del mejor rendimiento en el desempeño de la función. Pero, como se verá más adelante, esto no suponía que se excluyera de entrada la posibilidad de incorporar otras personas que no reunieran la condición de funcionarios públicos.
La otra cuestión, que desapareció después de haber sido aprobado en principio el texto por el Consejo de Ministros, tenía mayor importancia. Se refería a un trámite que se daba en el futuro a la Secretaría General Técnica, en forma de informe previo y preceptivo, en todas las disposiciones que modificaran la organización administrativa ${ }^{33}$. Lo que le otorgaba una posición predominante en esta materia sobre el resto de Ministerios. Sentado que la creación misma de la Secretaría General Técnica de la Presidencia del Gobierno era imparable por el apoyo directo que había recibido de Franco, fue la única cuestión que contó con mayor oposición por parte de algunos Ministros.

\section{b) La tramitación final del Decreto-Ley}

Con fecha 10 de diciembre Carrero envia por carta a todos los Ministros, con carácter personal y reservado, el proyecto de Decreto-Ley que será sometido a la deliberación del próximo Consejo de Ministros y en el que se propondrá para el desempeño de este cargo a D. Laureano López Rodó. Al principio de la carta justificaba sucintamente la creación del nuevo órgano: "a fin de proceder a un detenido estudio sobre la organización, funcionamiento y personal de la Administración pública, necesidad que desde hace tiempo se viene haciendo sentir, y cuya propuesta ha aprobado S.E. el Jefe de Estado, se ha decidido crear en la Presidencia del Gobierno una Secretaría General Técnica a la que se encomienda esta misión.

Observamos que Carrero, muy sintéticamente, comunica a sus colegas que se trata de un órgano de estudio sobre los tres aspectos esenciales de la Administración. Pero, sobre todo, que la propuesta ya había sido aprobada por el Jefe del Estado.

Inicialmente acusan recibo los Ministros de la Gobernación, Blas Pérez González, y de Información y Turismo, Gabriel Arias Salgado.

Y con posterioridad a la celebración del Consejo de Ministros, que tiene lugar el día 14 de diciembre y en la que formalmente se da por aprobado el Decreto-Ley, se reciben observaciones de los Ministros de Trabajo, José Antonio Girón de Velasco, y de Agricultura, Rafael Cavestany, ambos pertenecientes al sector falangista del régimen.

El Ministro de Trabajo envía con carta del 17 de diciembre una nota con observaciones. En resumen, se limita a solicitar que se clarifiquen las competencias que se atribuyen al nuevo órgano, y se delimiten respecto de las que corresponden a otros órganos e instituciones que en la actualidad ya tienen competencias sobre las que ahora se pretenden centralizar; así como el reconocimiento de las que en el futuro -y esto es muy importante - vayan a corresponder a los Ministros. Girón, sin duda, quería destacar de esta manera la indefinición funcional del nuevo órgano y cómo podría afectar su actividad a las 
atribuciones propias de los Ministros. Su táctica consistía, pues, en tirar por elevación para conseguir apoyos por parte de algunos de sus colegas.

Dos días más tarde, el 19 diciembre, el Ministro de Agricultura en una extensa carta formula con firmeza una observación de gran calado al contenido del proyectado artículo $4^{\circ}$. Las facultades que se otorgan a la futura Secretaría General Técnica chocan con su naturaleza de órgano de estudio. "La censura (sic) que se le encomienda - dice- no será ejercida en nombre de unos principios previamente declarados, sino de la opinión personal del titular de un organismo que no está en contacto directo con la necesidad que motiva la disposición. Por otra parte, no existen precedentes de una función de esta naturaleza. Esto no obstante, ofrece algunas alternativas: que se promulgue primero una Ley de Bases de Reforma de la Administración General del Estado, y las normas ministeriales que después hayan de introducir modificaciones en las tres materias tópicas, deberán ser previamente dictaminadas por el nuevo órgano de la Presidencia del Cobierno. Pero refiriéndose a su adecuación a la previa Ley de Bases. Y sólo cuando haya disconformidad es cuando se necesitará la expresa aprobación del Consejo de Ministros. Otras alternativas ofrecidas por el Ministro de Agricultura consisten en que la Secretaría General Técnica sólo emita dictamen cuando sea requerida para ello, es decir, con carácter facultativo; o que el dictamen se refiera a la adecuación de la disposición proyectada con las atribuciones del Departamento que las proponga o con las normas de la legalidad vigente. Sólo en caso de disconformidad es cuando habría que acudir al Consejo de Ministros.

Se ve, pues, que el propósito de conferir a la nueva Secretaria General Técnica una función de supervisión o control de las decisiones de los demás Ministerios en materias relacionadas con la organización administrativa, y sin unos límites o referentes previos, no contaba con el beneplácito, al menos, del Ministerio de Agricultura.

El hecho es que al dia siguiente, 20 de diciembre, el Decreto-Ley es aprobado por el Jefe del Estado habiéndose suprimido íntegramente el artículo $4^{\circ}$ que figuraba en el texto distribuido a los Ministros ${ }^{\text {kh. }}$.

Otra modificación introducida a última hora, también significativa, consistió en otorgar a la Presidencia del Gobierno, y no al Secretario General Técnico como figuraba en el texto previamente repartido, la facultad de poder solicitar de cualquier centro o dependencia de la Administración cuantos informes, dictámenes y gestiones estimara convenientes para el cumplimiento de su cometido.

Estas dos fueron las únicas modificaciones importantes que experimentó el Decreto-Ley después de su aprobación formal por el Consejo de Ministros. También hubo otras dos de menor entidad: intercalar el adverbio especialmente en el artículo 20 , antes de uen cuanto se refiere a la reforma y perfeccionamiento...•, y en el artículo $3^{\circ}$ sustituir •podrá disponer॰ por •podrá interesar. Y nada más.

El Consejo de Ministros nombra a López Rodó Secretario General Técnico de la Presidencia del Gobiemo a los tres meses justos de su conferencia en Santiago de Compostela. En aquel momento tiene 36 años de edad y, según consta en el currículum que había preparado para la ocasión, es enatural de Barcelona, donde cursó la carrera de Derecho. Se doctoró en Madrid con premio extraordinario. En 1945 obtuvo por unanimidad el núm. 1 en las oposiciones a cátedras de Derecho Administrativo, pasando a desempeñar la de Santiago de Compostela durante ocho años... Desde 1952 es Secretario Técnico del Consejo Superior de Investigaciones Científicas; en 1955 fue elegido Consejero del Pleno. Es también Secretario de la Junta de Estudios Económicos y Sociológicos del Consejo... Vocal del Consejo Superior de Protección de Menores... Es miembro del Instituto Internacional de Ciencias Administrativas y ha participado activamente en las reuniones de dicho Instituto celebradas en Lisboa, Knoke, Estambul y Oxford. En el X Congreso Internacional de Ciencias Administrativas ostentó la representación del Vaticano.... De las dos páginas y media en que ha sido redactado, casi dos están ocupadas exclusivamente por una relación completa de sus publicaciones. Aunque en la mayoría de los casos se trata de materias relacionadas con aspectos específicos sobre el funcionamiento de la Administración (la corporación de servicios; la discrecionalidad en la Administración; los contratos administrativos de obras públicas...), sobre todo la local, no aparecen trabajos monográficos sobre temas relacionados con la reforma administrativa. Salvo la cita, en antepenúltimo lugar, de la publicación en la revista Nuestro Tiempo de su conferencia veraniega sobre LLa reforma administrativa del Estadon.

\section{Los primeros y audaces pasos de la reforma administrativa}

\section{a) La llegada de López Rodó al antiguo Palacio del marqués de Villamejor}

LOPEZ RODó cuenta de manera muy ilustrativa ${ }^{35}$ su llegada al palacete del Paseo de la Castellana 3, sede de la Presidencia del Gobierno. O como indica el rótulo que siempre ha figurado en 
el frontis de la entrada al edificio por la calle Alcalá Galiano 10, en recuerdo de la II República: "Presidencia del Consejo de Ministros. Oficinas".

-Carrero me recibió con cordialidad el 17 - [de diciembre, es decir, el lunes siguiente a la aprobación del Decreto-Ley y de su simultáneo nombramiento por el Consejo de Ministros, y cinco días antes de su publicación en el B.O.E.)pero sin dar mayor importancia al asunto. Me dijo que me prepararían un clespacho en la planta superior y que, si lo necesitaba, podria tener una mecanógrafa para pasar a máquina lo que yo escribiera; que, si al cabo de unos meses, tenía hecho el estudio, bajara a despacharlo con él. La realidad, como enseguida se verá, fue muy otran.

$Y$ así lue. Testimonios de funcionarios que trabajaban en aquella época en la Presidencia del Gobierno aseguran que el Ministro, Carrero Blanco, pensaba que López Rodó era un prolesor universitario que se encerraría a estudiar en un despacho rodeado de libros. El propio Carrero, unos años después, al parecer comentaba su sorpresa cuando Laureano -así le llamaba- alteró la tranquilidad y sosiego que reinaban en aquella casa.

Porque la organización administrativa de la Presidencia era bien magra. Como recuerda LOPEZ RODO ${ }^{36}$

Antes de crearse la Secretaría General Técnica, la organización de la Presidencia del Gobierno, regulada por la Ley de 22 de diciembre de 1942, era muy elemental. Se componía de una Oficialía Mayor, seis Secciones - (entre ellas, Personal, Ordenación Económica, Agravios... $\vdash$ Habilitación, Asesoría Jurídica, y Archivo y Biblioteca. Su plantilla de personal era sumamente reducida: diecisiete funcionarios del Cuerpo Técnico-administrativo y trece del Cuerpo Auxiliar... En el palacete del Paseo de la Castellana no 3 trabajaban olos habitantes de la casa deshabitadan, que diría Jardiel Poncela.

Este comentario final de LOPEZ RoDo, paralraseando al lértil autor teatual, suena algo sarcástico. La realidad, casi inevitable por otra parte, fue que desde el primer momento salió a relucir entre los funcionarios preexistentes y los que iban llegando, una distinta concepción no sólo de la Administración y de las funciones que se debían desarrollar, sino también de la manera en que había de organizarse el trabajo en una dependencia pública.

Esta discrepancia entre la organización tradicional y los nuevos esquemas de quienes venían a encargarse, precisamente, de la reforma de la Administración, se refleja en un documento externo, preparado para lópez Rodó a propósito del crédito presupuestario inicialmente asignado a la Secretaría General Técnica para $1957^{37}$.

De entrada se afirma que,
"No es la Secretaría General Técnica un centru de gestión que tenga a su cargo el ejercicio de actividades administrativas preparatorias de actos administrativos considerados en sentido estricto, que conduzcan a la creación de situaciones individuales subjetivas que presupongan la instrucción de "expedientes", sino un Centro encargado de la elaboración, preparación y coordinación de disposiciones de carácter general, y por ello en los servicios que tiene a su cargo han de predominar los trabajos de estudios sobre los burocráticos propiamente dichos.

Esta acertada -aunque un poco hiriente- distinción tenía por objeto, principalmente, establecer unas fronteras claras y bien delimitadas con las actividades propias de la Oficialia Mayor y de las Secciones integradas en la misma. Que no parecian estar muy dispuestas a comprender, y menos a facilitar descle el plano administrativo, el papel reformador del nuevo órgano. En definitiva, lo que los especialistas en psicología de las organizaciones y en ciencias del comportamiento han calificado como resistencia al cambio. $\mathrm{O}$ al invasor, según se mire.

En el mismo documento se sientan las líneas generales de lo que había de ser la organización del trabajo en el seno de la Secretaría General Técnica: una reducida plantilla de personal procedente de los diversos cuerpos de funcionarios del Estado; un Gabinete de Estudios en el que se centralizarán las ponencias básicas de las disposiciones que prepare el organismo, y en el que ya se advierte que asu redacción se encomendará específicamente y para cada caso concreto, a quienes teniendo o no la condición de funcionarios públicos, se considere que pueden ser útiles para el desempeño de los trabajos que les sean encomendados"; y también el sistema para remunerar al personal, en el que el crédito que se consigna para las correspondientes dotaciones "no se fijan en ningún caso en concepto de ssueldos. imputables al artículo $1^{\circ}$ del capítulo I. La razón es bien clara: si se trata de funcionarios ya cobraban por este concepto en su Ministerio de procedencia, y en cuanto a quienes se encomiende la redacción de dictámenes y anteproyectos de disposiciones, porque su retribución no se hará nunca en forma de haber permanente percibido en forma periódica, o sea por mensualidades, sino por una sola vez y según las circunstancias de los trabajos que en cada caso se encomienden. Este nuevo régimen de retribuciones seguro que podía resultar difícil de entender, y más de aceptar, para los funcionarios permanentes y profesionales que constituían la única plantilla de la Presidencia del Gobierno en aquellos momentos, y cuyos ingresos se reducían a una casi simbólica cantidad en concepto de sueldo y a alguna esporádica, pero sobre todo escasa, gratificación.

Más adelante el documento se completa con una afirmación a propósito de las horas extraordinarias, que también tenía que molestar necesariamente a los funcionarios de la Oficialía Mayor, destinatarios del documento en cuestión: •El crédito que se 
destina a la retribución de trabajos realizados en horas extraordinarias se asigna únicamente para los que durante ellas realice el personal administrativo puesto que los que tenga asignados el personal técnico se retribuirán, como es lógico, en relación con la calidad de los servicios que preste y no por su permanencia en las oficinas durante un número de horas de trabajo".

Se asumía, pues, una distinción real, formal y social, entonces existente en todos los Ministerios, entre los funcionarios técnicos y los administrativos, que era origen de importantes desigualdades en cuanto a determinados aspectos de su régimen (dedicación, remuneraciones...). Que a su vez eran la causa de una soterrada confrontación de éstos contra aquéllos. El personal administrativo pretendia ir alcanzando más niveles de igualdad, mientras que a los técnicos sólo les interesaba mantener las diferencias a ultranza.

Esto significaba que no todo iban a ser facilidades - administrativas, por supuesto- para los nuevos inquilinos de la planta tercera del Paseo de la Castellana 3. De todas formas, las preceptivas molestias burocráticas no impidieron a lópez Rodó y a su menguado equipo realizar algunos estudios de un inmediato y espectacular éxito (como veremos a continuación), ampliar el inicial campo de actuación aparentemente técnico y extender su influencia al nivel político. A finales de 1957, en el ámbito del régimen español, casi nadie percibía ya a López Rodó como un mero profesor universitario encargado de la reforma técnica de la Administración. Y ello a pesar de la denominación de tecnócratas que recibieron los que casi inmediatamente se incorporaron a tareas gubernamentales a partir de la crisis de febrero de dicho año ${ }^{38}$.

Si existía alguna duda de la voluntad de López Rodó de intervenir directamente en la política nacional quedó aclarada, como veremos más adelante, con su relevante participación en la preparación del Decreto-Ley de 25 de febrero de 1957, sobre reorganización de la Administración Central del Estado, y que sirvió de instrumento para la renovación gubernamental -que no fue un simple cambio de guardia como en ocasiones anteriores ${ }^{39}$ - llevada a cabo en aquella fecha.

El propio LOPEZ RODO da en sus Memorias una visión retrospectiva del carácter que tenía el nuevo órgano ${ }^{\text {k0 }}$ :

-La Secretaría General Técnica de la Presidencia del Gobierno era algo más que un simple gabinete de estudios; era el motor de la reforma de las altas instancias de la Administración y de la implantación de las necesarias garantías jurídicas exigidas por un Estado de Derecho".

No parece que pueda discutirse algunos aspectos de esta última manifestación de López Rodó después de la aprobación de la Ley de Régimen Jurídico de la Administración del Estado, de julio de 1957, en la que se introducian como principios a que debía sujetarse la actividad administrativa el de legalidad, de jerarquía nor- mativa o el de inderogabilidad singular de los reglamentos. Y también se extendía y perfeccionaba la responsabilidad patrimonial de la Administración ya introducida en la Ley de Expropiación Forzosa de 1954, con la de las autoridades y funcionarios. 0 después en la Ley de Procedimiento Administrativo, de julio de 1958, de cuyo patrocinio directo e impulso entusiasta por parte de López Rodó nunca ha habido duda, y que estableció un completo régimen de recursos administrativos ordinarios y extraordinarios que podian utilizar los particulares contra los actos y disposiciones de la Administración.

Pero lo que sí puede resultar más cuestionable es la pretensión de elevar a principal inquietud del entonces equipo políitco de la Presidencia del Gobierno y, consecuentemente, a prioridad política, la de implantar las garantías jurídicas propias de un Estado de Derecho. Entre otras razones porque es evidente que aquel régimen no respondía plenamente a este modelo de Estado.

Desde esta perspectiva, cabría recordar que la llegada de López Rodó a la Presidencia del Gobierno en enero de 1957, no sólo levantó normales recelos en la zona más azul del régimen, en el Ministerio de Hacienda y entre los funcionarios de la Oficialía Mayor, por distintas causas y circunstancias. También suscitó suspicacias entre un determinado sector de la docencia universitaria, como veremos a continuación.

\section{a) La otra forma de reforma}

No fue infrecuente que algunos autores (Juan Luis DE LA VALLINA y Carlos MOYA, entre otros) sintetizaran el tratamiento doctrinal dado a la reforma administrativa de la época, en dos formas de entenderla que a veces se presentaban no sólo como antitéticas sino como irreconciliables. Tampoco era de extrañar pues ambas concepciones estaban patrocinadas por sendos catedráticos de Derecho Administrativo de la Universidad española: López Rodó y García de Enterría. Esta distinción, en cierta manera real pero sin llegar a extremos de radical diferenciación entre ambas, en algunas ocasiones llegó a presentarse desde perspectivas y planteamientos bien maniqueos.

Así, para la primera opción que salió triunfante parecía que el objetivo principal consistía en transformar una Administración antigua y anticuada en un instrumento idóneo al servicio del desarrollo económico y social. Para lo que siguió una doble línea de actuación: dotarla de un marco legal adecuado mediante la promulgación de indispensables leyes generales administrativas, y también a través de la importación de técnicas gerenciales propias del sector privado, que permitieran alcanzar mayor eficacia en la gestión de los servicios públicos.

En cambio, para la otra alternativa lo que debía hacerse era la racionalización política y jurídica del aparato administrativo, 
el control de la Administración, la protección de las libertades individuales y para ello la dirección de la reforma administrativa debería estar en manos de políticos y no de técnicos.

Descle este doble enfoque de la reforma administrativa no era difícil concluir que iban más allá de distintas concepciones cloctrinales sobre la manera de entender la Ciencia de la Administración, que era donde se inspiraba y se nutría el contenido de aquel proceso. No se trataba sólo de una mera discusión académica entre distintas escuelas del pensamiento administrativo, sino de planteamientos ideológicos y profesionales bien diferentes.

Y puede que así fuera, pero no cabe olvidar que la renovación del Derecho Administrativo español surgió principalmente en el Instituto de Estudios Políticos; éste fue el tronco común -el único entonces existente- del que surgieron la mayoría de los jóvenes profesores universitarios que asumieron la modernización del tratamiento jurídico y no jurídico de nuestra Administración.

Tampoco se debe olvidar que en la década de los cincuenta el Instituto de Estudios Políticos era uno de los mejores trampolines para lanzarse a la vida oficial española. Por lo que no es de extrañar que "en la nómina del Instituto figurase todo el que se preciaba ser miembro -o aspiraba a serlo- de la intelectualidad oficial española ${ }^{\prime 1}$. Y esto no quita para que después cada uno eligiera su propio camino en el contexto de la ciencia jurídica o política de nuestro país, o adoptara una actitud más posibilista o distante en relación con la evolución del mismo régimen.

Ya en el primer cuatrimestre de 1950 había aparecido el primer número de la Revista de Administración Priblica ${ }^{42}$. En la presentación se decía que

"la plenitud y madurez a que ha llegado la Revista de Estudios Políticos aconsejan desglosar de sus páginas los temas concretos referentes a la Administración del Estado... Cobran autonomía, pues, en la Revista que ahora aparece las cuestiones de ADMINISTRACION PUBLICA (Política, Ciencia, Derecho de la Administración) con intención de servir y poner de relieve su técnica y características propias... Para las dos vertientes de lo administrativo, que hacen relación, por una parte, al Poder, del que es más imprescindible y sutil instrumento, $y$, de otra, el administrado, a quien señala los límites y condicionamiento de su autonomía, ofrece nuestro tiempo una especial sensibilidad.

Sin embargo, Alejandro NIETO ${ }^{\text {i. }}$ ha reconocido que

“desde el primer momento - y apenas sin excepciones - la Revista renunció a su ambiciosa temática para volcarse en un solo y concreto aspecto: el jurídico... el contenido de la RAP no responde, en rigor, a su título, y quizá hubiera re- sultado más apropiado el de •Revista de Derecho Administrativo", puesto que notoriamente ha estado escrita siempre por y para juristas... Por otro lado - y en contra también del anuncio hecho en la presentación-, igualmente se echan en falta los estudios dedicados a la "Ciencia de la Administración. "4i.

Pues bien, según palabras del propio Alejandro NieTo, quienes se agruparon en torno a esta Revista pretendieron vla creación de un Derecho Administrativo nuevo, inspirado en las realidades concretas del presente y del futuro. No necesitaron para ello, a la manera de otras ramas humanísticas, la proclama de manifiestos teóricos ni el anuncio a bombo y platillo de actitudes de ninguna clase, ni la voluntad de constituirse como grupo o escuela. Consistió en otro tipo de planteamiento, más respetable con la libertad e independencia de cada quien. Pues si algo en común tenían al margen de su afición por renovar el Derecho Administrativo español, era su tolerancia y comprensión con las opiniones ajenas".

Más que de una insalvable diferencia doctrinal de partida entre la posición de unos y otros, podía tratarse de una simple y diferente estrategia impuesta por la marcha de los acontecimientos. Al aparecer López Rodó como director general de la Presidencia del Gobierno, no ofrecía duda que había expresado claramente su apoyo a favor de una determinada opción política dentro del régimen ${ }^{45}$. Opción política que, por las razones que fueran, ni compartía ni afectaba a la mayor parte de los contertulios del Instituto de Estudios Políticos, a pesar de su dependencia de la Secretaría General del Movimiento.

Pero desde el punto de vista de los aspectos jurídicos y no jurídicos de nuestra Administración, ni López Rodó rechazaba la necesidad de una mayor racionalidad jurídica y control de la Administración, como lo demuestran los textos legales que patrocinó, ni GarCía DE ENTERRía ocultaba su deseo de que no se soslayara el mérito de su equipo más próximo en la importación de las nuevas técnicas gerenciales y afines que entonces empezaban a integrar una Ciencia de la Administración actualizada en nuestro país ${ }^{46}$. Y que constituían uno de los pilares sobre los que se asentaba la reforma administrativa oficial.

El propio Alejandro NIETo, poco sospechoso de afinidades con aquel régimen político, comenta:

.Pues no hay que olvidar que en la década de 1950 es cuando han aparecido las leyes administrativas mejor hechas técnicamente y que en parte son debidas directamente a la pluma de los hombres de la RAP: la ley de expropiación forzosa, la del suelo, la reguladora de la jurisdicción contencioso-administrativa ${ }^{\text {} 7}$, la de procedimiento administrativo y tantas otras".

Podía resultar paradójico que fuera precisamente el Instituto de Estudios Políticos, que en otro ámbitos de su organización 
defendía posiciones totalitarias en cuanto a la institucionalización política del régimen, el patrocinador de leyes administrativas de factura garantista. Pero tenía su explicación. Alejandro NIETO, a propósito de los profesores que se agruparon en tomo a la Sección Administrativa del Instituto y a su Revista, recuerda que

-la RAP nació como una Revista rigurosamente técnica, neutral e independiente... el Instituto de Estudios Políticos ha hecho también cuestión de honor el respetar la integridad y la independencia de criterio de la Revista que publicaba. Esto es algo muy conocido que hasta ahora nadie se ha atrevido a poner en duda. Pero conviene airearlo una vez más en alabanza de las dos partes y como ejemplo, dificilmente superable, de juego limpio.

De todas formas, la creación de la Secretaría General Técnica de la Presidencia no fue vista con buenos ojos por el Instituto de Estudios Políticos y la Secretaría General de Movimiento ${ }^{48}$. Y tenía su lógica, al margen de discrepancias doctrinales, ideologías y estrategias políticas. Hasta ese momento el protagonismo, casi el monopolio técnico por decirlo de manera más metafórica, en la preparación de borradores de las leyes administrativas (como las que se acaban de citar) habia correspondido al Instituto; en el futuro parecía obvio que sería asumido por el nuevo órgano. Y la cuestión tenía su trascendencia desde muchos puntos de vista.

La llegada de López Rodó a la Presidencia del Gobierno suponía, de entrada, entre otras cosas, que el centro de gravedad de determinado poder político, en el que se podía incluir la capacidad de lege ferenda sobre el aparato del Estado, había empezado a desplazarse desde la Plaza de la Marina Española al Paseo de la Castellana.

No es, pues, de extrañar que se produjera una cierta controversia, incluso confrontación en algunos momentos, entre ambas escuelas o grupos académicos. Y que ahí precisamente resida el origen de una construcción conceptual sobre las dos maneras diferentes de entender la reforma administrativa.

Después de transcurridos más de cuarenta años desde aquellos acontecimientos hay que evitar cualquier tentación de reescribir la historia, y menos resucitar antiguas rivalidades y protagonismos entre cátedras y escuelas. Pero tampoco está de más aventurar que con aquel contencioso supuestamente académico no se trataba sólo de discutir y defender distintas posiciones ideológicas y sus correspondientes estrategias. También se ventilaba algo más prosaico pero no menos necesario: la respectiva situación de cada quien y de sus respectivos grupos dentro del organigrama del poder actuante. Lo que no era cuestión baladí.

\section{b) Un éxito inicial a propósito de una crisis de Gobierno}

Si López Rodó tuvo que desistir de sus propósitos coordinadores en el Decreto-Ley aprobado el 20 de diciembre de 1956, eso no significaba que hubiera renunciado a ellos. Sabía el valor e importancia que podía representar esta atractiva pero dificilmente alcanzable función, para consolidar la posición de la Secretaría General Técnica y, por lo tanto, su poder personal en el ámbito de la Administración del Estado. En el preámbulo del Decreto-Ley de 19 de julio de 1951, que otorgó rango de Ministro al entonces Subsecretario de la Presidencia para que pudiera asistir como Secretario a las reuniones del Consejo de Ministros, ya se decía que el aspecto de la acción coordinadora que tradicionalmente corresponde a los asuntos que a la Presidencia del Gobierno competen, al intensificarse hoy especialmente por cuanto afecta a los programas de Ordenación Económico Social elaborados por la Presidencia del Gobierno, asi como las múltiples cuestiones de competencia y recursos que a la misma específicamente corresponden.... Resulta un tanto chocante, a la par que esclarecedor, que se hayan situado al mismo nivel en cuanto a la justificación de la elevación del rango ministerial, unos programas de ordenación económico-social y la resolución de unos expedientes administrativos sobre cuestiones de competencia y recursos. En cualquier caso, puede resultar un buen indicador de la similar preocupación con que ambas cuestiones eran sentidas en aquella organización.

Pero la realidad había sido otra ya que la coordinación interministerial no era el principal valor predicable de la Administración española en los primeros años de la década de los cincuenta.

Por lo tanto, la panacea de la coordinación para remediar muchos de los males de la Administración, además de ser un planteamiento oportuno y un intento aconsejable, podía dar buenos réditos. La primera ocasión no tardó en llegar.

La intención de una amplia crisis gubernamental, que venía desde 1955, fue abortada - como ya se ha dicho- ante la necesidad de sustituir a dos ministros, después de los incidentes estudiantiles de febrero de 1956. Pero esta remodelación parcial no arregló la situación política que se vio aún más deteriorada por el fracaso de los proyectos institucionalizadores de Arrese, el agravamiento de la crisis económica, la creciente agitación social con huelgas en las principales ciudades industriales del país, la improvisada e inmediata independencia de Marruecos... Sin olvidar la supuesta conspiración monárquica, si es que merece tal calificación, en la que estaba involucrado el capitán general de Cataluña, Juan Bautista Sánchez, fallecido en circunstancias tan extrañas que dieron pábulo a todo tipo de interpretaciones y especulaciones políticas.

López Rodó, a mediados de enero de 1957, había circulado un .Informe acerca de la reorganización de la Administración 
del Estado. que llega hasta Franco, en el que insiste sobre la necesidad de coordinación político-económica y administrativa entre los Ministerios, que es preciso vincular a la Presidencia del Gobierno. En cuanto a la futura configuración de ésta toma como punto de partida la unión personal entre el Jefe del Estado y el Presidente del Gobiemo, para afirmar con toda audacia que la ingente labor de coordinación, impulso y control es imposible hacerla recaer en la misma persona. A continuación propone la figura de un Ministro de la Presidencia que asuma las funciones de coordinación y programación. Incluso llega a mantener que este Ministro de la Presidencia adebiera estar en un plano superior al de los demás Ministros, en vez de ser un simple Subsecretario de la Presidencia, con categoría de Ministro, que es lo que entonces era Carrero. También sugiere que se adscriba a la Secretaría General Técnica el Secretariado del Gobierno, un Gabinete de Estudios de la Reforma Administrativa y una Comisión de Coordinación y Progmmación Económica. En cuanto a la nueva división ministerial, las novedades más relevantes que ofrece eran la creación de dos nuevos Ministerios (de Transportes y Comunicaciones, y de Sanidad y Previsión Social), la incorporación del sector Vivienda a Obras Públicas, y el de Energía y Combustibles a Industria, y la supresión del Ministerio de Información y Turismo. Y para concluir, y dentro del apartado dedicado a los organismos de coordinación interministerial, propugnaba la creación de Comisiones de Ministros y también de Subsecretarios. El Informe de lópez Rodó supone una buena sacudida a las obsoletas estructuras administrativas de la organización ministerial.

Planteamientos tan normales y sencillos, por no decir de sentido común, fueron considerados por algunos sectores de régimen político como excesivamente innovadores, próximos a una renovación radical -a una revolución blanca- que había de alterar profundamente la sosegada y tranquila realidad de la Administración estatal.

A pesar de ello, López Rodó recibe de Franco directamente, con motivo de la protocolaria y obligada visita al Jefe del Estado después de su nombramiento, el encargo de redactar un proyecto de ley que recogiera las principales ideas expuestas en su Informe. Y ante las noticias de que se estaba gestando una crisis de Gobierno, el Secretario General Técnico de la Presidencia cambia de táctica sobre la marcha y plantea la posibilidad de que la nueva división ministerial sea realizada mediante decreto-ley. El resto de las medidas para la reorganización de la Administración del Estado constituirían el contenido de un proyecto de ley, que se enviaria a las Cortes para su normal tramitación. Y a posteriori se refundirían ambos textos en uno sólo, con lo que la materia propiamente dicha, el nuevo régimen jurídico de la Administración del Estado, recuperaría su unidad inicial ${ }^{\text {19. }}$.
A pesar de las reticencias iniciales del Jefe del Estado para que se utilizara de nuevo la vía del Decreto-Ley en menos de dos meses ${ }^{50}$, fue publicado en el B.O.E. de 26 de febrero de 1957. Constituyó un clamoroso éxito personal de López Rodó. Y no tanto porque en él se recogieran gran parte de las ideas que había expuesto escasos meses atrás en la conferencia que pronunció en Santiago de Compostela (como la creación del Ministerio de la Vivienda, de las Comisiones Delegadas del Gobierno, de la Oficina de Coordinación y Programación Económica o una Dirección General encargada de la Energía Nuclear, así como la posibilidad de constituir Comisiones de Subsecretarios), como porque había reforzado formalmente el papel coordinador de la Presidencia del Gobierno, a través de la figura preexistente del Ministro Subsecretario. Si bien no consiguió la pretensión de que Carrero alcanzara una posición cercana a la de vicepresidente del Gobierno, al menos le facilitó la de primis inter pares, la realidad es que le situó en condiciones para que pudiera convertirse en un superministro a través de diversos mecanismos indirectos.

Entre ellos, por ejemplo, se encomendaba a la Presidencia del Gobierno dar unidad a la acción política y administrativa general y coordinar la actividad de los distintos Departamentos, para lo que el Presidente del Gobierno estaría asistido del Ministro Subsecretario; expresamente se le atribuía la Secretaría del Consejo de Ministros ${ }^{\text {s1; }}$ se le encomendaba -con una fórmula cabalistica pero hábil- la presidencia de las Comisiones Delegadas en representación del Presidente del Consejo (sic; ¿un lapsis republicano?); era el Presidente nato de las Comisiones de Subsecretarios que pudieran constituirse y de la Comisión que dirigía la Oficina de Coordinación y Programación Económica, embrión de la posterior Comisaría del Plan de Desarrollo; el Boletín Oficial del Estado (todo con mayúsculas en el texto publicado en el periódico oficial) pasaba a depender, *a todos los efectos", de la Presidencia del Gobiemo.

En suma, el reforzamiento político de Carrero Blanco y, por lo tanto de López Rodó, principal artífice del contenido material del Decreto-Ley, en principio no ofrecía duda. Se había dotado a la Presidencia del Gobierno de un marco legal de actuación, so pretexto de la coordinación, que permitía el control administrativo de la actividad de los Ministerios desde el palacete de Castellana, 3.

Si Carrero, desde 1951 en que había accedido a la condición de Ministro, ya se había acreditado como uno de los principales consejeros de Franco para asuntos de gobierno, empezaba a quedar patente con la entronización de López Rodó como recién acreditado taumaturgo político-administrativo, que éste no iba a autolimitarse y jugar un papel exclusivamente tecnocrático, de hacedor de reformas administrativas. Evidentemente que su propósito, lógico por otra parte, era ganarse la confianza de Carrero para convertirse, a su vez, en su consejero principal 
para todas las cuestiones que se refirieran tanto a la organización del Estado como a la economía del país. Y así sucedió ${ }^{52}$.

De todas formas, y aunque en principio pudieran parecer cuestiones menores, conviene destacar otros dos aspectos importantes del Decreto-Ley. El primero, que junto con los Ministros titulares de cada Departamento se daba formalmente entrada a los Ministros sin cartera. Y a continuación el precepto declara que "el Ministro Secretario General del Movimiento tiene el carácter de Ministro sin cartera". Con lo que se establecía un claro deslinde entre la organización administrativa del Movimiento Nacional y la estructura orgánica de la Administración Central del Estado. En el futuro, ya nada que tendría que ver ésta con aquélla ${ }^{53}$.

Distinta significación tiene el "derecho de peaje. (infimo si se tiene en cuenta la carga política que contenía el Decreto-Ley) que hubo que pagar al Ministerio de Hacienda para conseguir una aprobación pacífica del Decreto-Ley. Y sobre todo un diligente y eficaz desarrollo presupuestario para efectuar transferencias y habilitar nuevos créditos, si tenemos en cuenta que habría que dotar mayores medios personales y materiales, en definitiva, presupuestarios, para las nuevas misiones que se encomendaban a la Presidencia del Gobierno. Al final del texto normativo del Decreto-Ley, y bajo la rúbrica de "Otras reformas orgánicas", hubo que incluir también la creación de la Secretaría General Técnica del Ministerio de Hacienda.

Éste vio con recelo desde el primer momento el creciente protagonismo que a partir del otono del año anterior se iba concediendo a la Presidencia del Gobierno en materias que, hasta aquel momento y por vía presupuestaria, eran de su única y exclusiva incumbencia más que competencia. Lógicamente, en términos de poder dentro de la organización y funcionamiento de toda la Administración pública, aquella novedad podia suponer una alteración de la relación de fuerzas existentes en el sector público estatal. No era, pues, trivial ir tomando posiciones ante los acontecimientos que se avecinaban. $Y$ la primera, obvia aunque sólo fuera por simple mimetismo, consistió en crear también otra Secretaría General Técnica en el propio Ministerio. Además, aprovechando una norma del mismo rango legal —un decreto-ley - que la que, en diciembre pasado, habia creado la de la Presidencia del Gobierno.

En definitiva, estamos ante la primera manifestación de un antagonismo político y administrativo, que en múltiples ocasiones derivó en enfrentamientos que crearon un clima de rivalidad latente entre la Presidencia del Gobierno y el Ministerio de Hacienda. Y que alcanzaron su momento más apoteósico con motivo de la aprobación del texto articulado de la Ley de Bases de Funcionarios Civiles del Estado, en lo relativo a la constitución de una Comisión Superior de Personal y a la formación inicial del Cuerpo Técnico de Administración civil. Los demás Ministerios empezaron a tener que soportar las consecuencias de esta rivalidad, ya que la ansiada coordinación era fácil de predicar pero difícil de practicar entre ambos Departamentos.

La reforma orgánica - primera de las tres en que había de desarrollarse la reforma administrativa - que había anunciado López Rodó en Santịago de Compostela, se había puesto en marcha con un paquete de medidas de fuerte impacto en la organización y funcionamiento de la anquilosada y somnolienta Administración de la época.

López Rodó se había acreditado, de entrada, no sólo como un buen técnico con gran capacidad de redacción normativa (preparar una disposición de carácter general resulta relativamente sencillo, si se hace de una manera escueta y funcional), sino como una persona que en dos meses escasos había sabido introducirse en el núcleo principal del poder político y administrativo del régimen. Con lo que había empezado a hacer realidad sus propósitos iniciales de reforma.

\section{d) Otras reformas legales a corto y medio plazo}

El éxito alcanzado con la reordenación de la Administración Central del Estado mediante la promulgación del Decreto-Ley de 25 de febrero de 1957, sirvió de espaldarazo inicial para los más inmediatos propósitos y proyectos legislativos de López Rodó. De momento suponía que había que completar en breve plazo el contenido del Decreto-Ley con lo que faltaba para conformar el régimen jurídico de la Administración del Estado.

Y así se hizo. El 10 de abril el Gobierno acordó remitir a las Cortes Españolas el correspondiente proyecto de Ley. El texto preparado, aparte de la mejora que podía suponer para acomodar la estructura y funcionamiento de los órganos de la Administración central a las modernas corrientes doctrinales existentes en Europa, permitió un nuevo impulso tanto para el lanzamiento político de López Rodó, en cuanto artífice de la reforma administrativa, como para la consolidación del Ministro Subsecretario de la Presidencia del Gobiemo, Carrero Blanco. Aunque en este último caso, ya había alcanzado una posición política muy reforzada desde la nueva reordenación de la Administración Central y de la coincidente crisis de Gobierno del mes de febrero.

La Ley es definitivamente aprobada en el Pleno de 15 de julio de aquel año. $Y$ sin duda significó un notorio avance en el proceso de institucionalización de la Administración estatal, aproximándola, como acabamos de decir, a otros modelos europeos

La mera enunciación de sus novedades permite valorar el alcance y trascendencia que la Ley debió tener en aquel momento para el régimen de Franco: sienta el principio de la personalidad jurídica única de la Administración; contiene una enumeración de las competencias del Consejo de Ministros, el 
Presidente del Cobierno (que, por primera vez, aparece separado orgánicamente de la Jefatura del Estado), los Ministros, Subsecretarios, Directores Generales y Secretarios Generales l'écnicos, cuya posible existencia se extendió a todos los Ministerios civiles; la delegación de atribuciones y desconcentración de funciones; el régimen jurídico de las disposiciones y resoluciones administrativas, con la enunciación de los principios de jerarquía normativa, legalidad e inderogabilidad singular de los reglamentos; y la responsabilidad del Estado, y de sus autoridades y funcionarios. Es decir, un verdadero código administrativo para ordenar la organización y actividad de la Administración, en sus líneas más generales, que sin duda suponía un notorio avance jurídico respecto de la situación de partida.

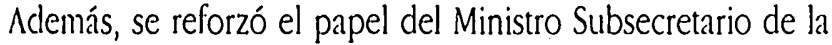
Presidencia en las materias convencionales de la reforma administrativa, al encomendarle - bien es verdad que por delegación ordinaria del Presidente del Gobierno- competencias tales como las de uproponer, conocer y elaborar (infinitivos bien escogidos) cuantas disposiciones se dicten sobre estructura orgánica, métodos de trabajo, procedimiento y personal de la Administración pública, así como velar (nuevo infinitivo de, en principio, escasa eficacia prescriptiva) por el cumplimiento de las vigentes"; o la de "cuidar (icuantos tira y afloja debieron producirse hasta consensuar éste tan inocuo!) de la selección, formación y perfeccionamiento de los funcionarios civiles del Estado no pertenecientes a Cuerpos especiales y, en general, todo lo relativo a su régimen jurídico. Funciones tan razonables fueron la semilla que más tarde fructificó en las Leyes de Procedimiento Administrativo y de Funcionarios Civiles del Estado, y que dotó a los órganos dependientes del Ministro Subsecretario de poder e influencia para participar e intervenir en la marcha de los servicios de los demás Ministerios.

Al margen de estos relevantes y meritorios aspectos técnicos, el proyecto de Ley facilitó, primero, a López Rodó, en calidad cle delegado del Ministro Subsecretario de la Presidencia, la oportunidad de comparecer ante la Comisión especial que, presidida por el ex Ministro de Educación y Presidente del Consejo de Estado, José Ibánez Martín, se había constituido para emitir dictamen. (Fue el bautismo político de fuego de LOPEZ RODo, del que ha dejado oportuna constancia en sus Memorias ${ }^{51}$ ). Y, en segundo lugar, permitió la comparecencia de Carrero Blanco ante el Pleno de las Cottes. Esta comparecencia tuvo un significado muy especial ya que, por primera vez desde que había sido nombrado Ministro en 1951, le permitió pronunciar un discurso en el que pudo expresar sus ideas políticas tal y como las sentía ${ }^{55}$.

\section{El pensamiento político de Carrero Blanco}

Del contenido del proyecto de Ley que Carrero tenía que presentar apenas dijo nada. Al final, se limitó a citar el discurso de Luis Sánchez Agesta quien, en nombre de la Comisión, le había antecedido en el uso de la palabra para exponer cuanto afectaba al aspecto técnico de la Ley. Carrero sólo dijo que se trata de un primer escalón hacia el logro de una Administración que sirva con máxima eficacia a la nación. Pero sobre la Ley de Régimen Jurídico de la Administración del Estado, nada más. Hay que reconocer que no fue mucho.

En cambio, hizo un extenso discurso en el que compendió la esencia de la doctrina del régimen de Franco, porque la realidad es que también fue una exaltación recurrente de la figura del Caudillo.

Inicialmente dedicó unos escasos minutos a explicar la finalidad de la reforma administrativa. Parte, sin duda, preparada por el propio López Rodó, pues existen referencias a la necesidad de lograr el máximo rendimiento del instrumento administrativo como "fenómeno común a todos los Estados", a las reformas anteriores (Leyes de expropiación forzosa y de la jurisdicción contencioso-administrativa), a la consolidación de instituciones administrativas eficientes, al papel de la Secretaría General Técnica recién creada y a cómo sus estudios irían cristalizando en proyectos de Ley sobre distintas materias que afectan al conjunto de la Administración... Pero inmediatamente el discurso empezó a adentrarse en el ámbito de lo político, zona que no abandonó durante la hora larga que duró su intervención.

Es más, en algunos momentos, a pesar de la prudencia, modestia y timidez que eran rasgos propios del carácter de Carrero Blanco que influían decisivamente en su conducta pública, parecía como si fuera el discurso que un Primer Ministro expone ante el Parlamento con su programa de Gobiemo. Por ejemplo, cuando aludió a la disposición del Gobierno *a reducir en lo indispensable los gastos improductivos del Estado, pero también a hacer que los particulares de economía desahogada frenen igualmente sus gastos innecesarios y contribuyan al Estado en proporción a sus ingresos. Y continuó hablando, obviamente en nombre del Gobierno, sobre la necesaria restricción del gasto público sin que ello afectara a determinados aspectos de la política social.

Carrero no eludió cuestiones difíciles como la de completar las Leyes Fundamentales (que tantos quebraderos de cabeza habían costado al ahora Ministro de la Vivienda, José Luis Arrese), en el sentido de que "están en estudio, y en su momento serán sometidas a la consideración y aprobación de las Cortes, las otras leyes fundamentales que, completando el cuadro de las actualmente en vigor, regulen las atribuciones y relaciones entre la Corona y los más altos órganos del Régimen ; o cuando aludió a لla preocupación de qué pueda suceder cuando el Caudillo falte. 
El discurso, en un tono constante de paternalismo autoritario, voluntarismo ingenuo y providencialismo religioso, fue una extensa pero sencilla exposición de cómo Carrero -es decir, en esta materia, Franco- concebía el Movimiento Nacional y la democracia orgánica. Las invocaciones a la unidad fueron reiteradas, constantes y casi obsesivas ("cuando los españoles hemos estado unidos, hemos sido invencibles., llegó a afirmar), referidas no sólo a las fuerzas integradas en el régimen (da unidad del Movimiento Nacional, es decir, la unión indestructible, alrededor del Caudillo, de todos los españoles que acaten sin la más mínima reserva mental su autoridad y sus decisiones" 0 -nada podrá suceder nunca a nuestra Patria, y todas las especulaciones de nuestros enemigos serán vanos cuentos de la lechera si sabemos mantener la unidad del Movimiento Nacional.), sino también al mundo empresarial (.cuando nuestros obreros, técnicos y empresarios formen una piña en cada empresa y alrededor de ella se sientan estrechamente unidos»). Hasta llegó a recordar la consigna dada por el Caudillo en los graves momentos del aislamiento internacional, de orden, unidad y aguantar. Y no faltó la ocasión para arremeter contra el Estado liberal ${ }^{56}$, los partidos políticos (.los partidos que en nosotros, habida cuenta de nuestra peculiar manera de ser, acaban en partidas, en atomización y en desastre.), o contra los enemigos del régimen en general (no hay que alarmarse demasiado porque la polilla exista; lo que hay que hacer es combatirla para que no dañe.).

El lenguaje utilizado por Carrero fue coloquial, sencillo y directo, lleno de metáforas (como las del violín; la del señor que protesta por los servicios de un casino y no paga la cuota reglamentaria; el maná llovido del cielo; la polilla; o el cuento de la lechera), de citas históricas (sobre el talón de Aquiles o la cabellera de Sansón; las trompetas del Apocalipsis; el acta de Bayona y la guerra de la Independencia; don Pelayo y la conquista de Granada), y de los tópicos usuales a favor de los fieles y en contra de los enemigos políticos (nosotros no tenemos por qué copiar a nadie; pequeño grupo de enredadores; los buenos españoles; rojos exiliados en su mendicidad de contubernios absurdos; enredos de media docena de insensatos). Así como de referencias salpicadas en loor de Franco, cuya frase más paradigmática fue la siguiente:

Todo lo hecho, en todos los órdenes, es obra del Caudillo y si lo logrado no ha sido mejor en algunos aspectos ha sido por deficiencia humana, porque sus colaboradores no hemos sabido ejecutar mejor las directrices dadas por él. No se trata de una burda lisonja. Ya he dicho en otra ocasión, desde esta misma tribuna, que creo que Dios nos concedió, como premio sin duda al sacrificio de nuestros caídos, como compensación a tanta sangre de héroe y mártir, a tanta lágrima de mujer y a tanta angustia de huérfano, la inmensa merced de un Caudillo excepcional que sólo podemos valorar como uno de esos regalos que, por algo muy grande, hace la Providencia a las naciones cada tres o cuatro siglos.

No tratándose de una burda lisonja, como dijo (y no hay por qué dudar de la sinceridad del propio orador), resulta difícil aceptar que, tras un proceso de convencimiento intelectual, se pueda llegar a sentir una veneración casi sobrenatural, religiosa, hacia un superior jerárquico, por muy carismático que sea.

El tono y el contenido del discurso andaba entre la homilía de domingo desde el púlpito de una parroquia de clase media y la charla familiar alrededor de la mesa camilla en el cuarto de estar de una casa de la burguesía española. Tampoco fue intemumpido con aplausos u otros gestos de agrado o entusiasmo durante el mismo, lo que no era inusual en aquella época. Después del discurso muchos procuradores - y la clase política del país- podian estar convencidos de que el pensamiento político de Carrero Blanco era simple, sin matices, integrista si se quiere y, sobre todo, poco elaborado y novedoso. Pero también sabían que era el pensamiento del propio Franco. Y que la primera ocasión para expresarlo, después de los últimos intentos falangistas por la dominación de las más altas instituciones del régimen y de la crisis de Gobierno, había sido la aprobación de una ley administrativa aparentemente técnica, inocua por su escaso contenido político: la del Régimen Jurídico de la Administración del Estado. A la que, además, Carrero Blanco no se había referido para nada.

\section{Un proyecto técnico para López Rodó}

La segunda oportunidad de proyección política —esta vez para López Rodó, ya designado procurador en Cortes- provino de la aprobación de la ley de Procedimiento Administrativo, a cuya preparación se habían dedicado intensamente los colaboradores del Gabinete de Estudios para la Reforma Administrativa, dirigidos por Antonio Carro Martínez, letrado del Consejo de Estado y profesor adjunto de Derecho Político de la Universidad Complutense.

Su elaboración interna fue bastante abierta, como puso de relieve el propio López Rodó en su discurso ante el Pleno de las Cortes Españolas, de 15 de julio de 1958 (es decir, justamente un año después de la aprobación de la Ley de Régimen Jurídico de la Administración del Estado). Al expresar que había sido el resultado de un trabajo en equipo se refirió específica y elogiosamente no sólo a sus colaboradores directos del Gabinete ${ }^{59}$, sino también al Instituto de Estudios Políticos, al grupo de abogados del Estado designados por la Dirección General de lo Contencioso, al Consejo de Estado en pleno y a los funcionarios de los distintos Ministerios que habían circulado observaciones. Contemplado desde esta perspectiva, el anteproyecto habría sido arropado con todos los sacramentos que permitían garantizar su calidad técnica. 
El discurso de López Rodó ante el Pleno de las Cortes Espanolas fue bueno. Pero sobre todo fue un discurso inusual en aquel hemiciclo. Y no tanto por la materia a que se refería (el procedimiento en la Administración Pública), sino por el enfoque y estructura que le dio.

Tuvo la inmensa habilidad de que, a pesar de la aridez de la materia, hizo una exposición amena e interesante, en la que mezcló en proporciones adecuadas las referencias históricas (contexto políico, económico y social de la anterior Ley de 1889) con aspectos conceptuales, tales como el tránsito del Estado liberal (al que no criticó, como era costumbre, como el principal causante de los males de la patria) al Estado social de Derecho. La obligada referencia al Estado Nacional español fue mínima, y se circunscribió a incorporarle a la nómina de Estados modemos con amplias políicas sociales (educación, sanidad, urbanismo, comunicaciones, desarrollo económico...), y a la necesidad de contar para ello con una Administración que consecuentemente no respondiera a un esquema liberal ya superado.

Como era inevitable, hizo una breve disquisición doctrinal, ortodoxa, para distinguir Administración y Política (una Administración sin Política carecería de rumbo. Pero la Política sin Administración tiene otro nombre: utopía*), refiriéndose también a la reforma administrativa española y a las principales realizaciones llevadas a cabo hasta ese momento. Y después de este amplio y didáctico preámbulo entró en la estructura y directrices del proyecto.

López Rodó apuntó cuatro ejes centrales de la Ley que presentaba: unidad y flexibilidad del procedimiento; simplificación de trámites e incremento de la productividad; colaboración de los administrados; y reducción del número de disposiciones reglamentarias.

Se trataba, pues, de una exposición marcadamente técnica, salvo al final, en que hizo una breve y oportuna referencia a la política del régimen para, a propósito de la actitud y talante de los funcionarios españoles en orden a la modernización y eficacia de la Administración y de la vida española, afirmar que

- una moral asi es la que hoy nos exige a todos la gran empresa del Movimiento Nacional. Sólo con ella podrá el hombre español trabajar día a día, con la ilusión de quien se sabe empeñado en la tarea de servir al bien común y al engrandecimiento de la Patria. Esta ejemplaridad silenciosa en la labor diaria, es, sin duda, el signo distintivo de toda gran política de realidades.

Ésta fue la única concesión que hizo a la retórica del momento. En cambio, la parte técnica de la exposición estuvo llena de frases brillantes, aforismos jurídicos y máximas propias de la sabiduría popular. Tales como:
aLas normas jurídicas han de ser pocas, breves, coherentes y han de responder a un criterio claro... prevalece el criterio unitario len la Ley] pero sin caer en un uniformismo exagerado... el procedimiento administrativo no puede concebirse como una cartera de obstáculos. . .la forma es la superación del caos, pero el formalismo es la descomposición de la forma... la nueva Ley pretende dar fuerza jurídica a una serie de principios que aumentan el rendimiento de la gestión administrativa y abaraten el coste...el Derecho Administrativo ha evolucionado en los últimos tiempos en el sentido de pasar de un sistema de limitaciones a un sistema de participación de los interesados...en contraste con una Administración remisa a veces en la resolución de las instancias de los particulares, se observaba el fenómeno de una perturbadora proliferación de reglamentos y demás disposiciones administrativas.

También dio prueba de su capacidad dialéctica cuando afirmó que la mayor parte de la Ley era aplicable a la Administración militar:

....No se trata, pues, de aplicar una Ley de Procedimiento a los tres Ejércitos, sino a la actividad administrativa que desarrollan sus respectivos Departamentos ministeriales, en cuanto órganos de la Administración Central.

Y para reforzar la idea de incluir en el ámbito de aplicación de la Ley a la Administración militar, utilizó el apoyo de un argumento político insólito:

-De este modo viene a subrayarse el principio de unidad, característico del espíritu del Movimiento.

Sin olvidar el guiño que hizo al final a los pacientes procuradores:

-No quiero dejar de presentarles mis excusas por la aridez de la exposición, que ha sido implacable pese a la hora y al calor; y por haber jugado con ventaja, ya que ésta fue en mis años de estudiante la hora de la clase de Derecho Administrativo.

Ahora resulta difícil ponderar el efecto que produjo en el hemiciclo de entonces el discurso que pronunció López Rodó. Pero no resulta arriesgado anticipar que el estilo claro, sencillo, sobrio y brillante de aquel joven catedrático de Derecho Administrativo, tuvo que suponer un revulsivo y un alivio para aquellos oídos tan cansados y agotados por la obligación impuesta de tener que escuchar tantas veces la monótona doctrina oficial.

López Rodó, con aquel discurso y la aprobación de la Ley de Procedimiento Administrativo, sólo con un voto en contra, había obtenido el doctorado en la política del régimen ${ }^{58}$. Pero sobre todo estaba renovando un viejo estilo de hacer política y continuaba su ascensión, lenta pero firme, por los escalones del poder. 
Claro que -como dice Ricardo DE LA CIERva- el MinistroSubsecretario Carrero Blanco «estaba cada vez más rendidamente tras él. ${ }^{59}$.

\section{Otros proyectos para Navarro Rubio}

También 1958 trajo la aprobación de otras dos leyes que, aunque no habian sido elaboradas bajo el patrocinio inmediato de la Secretaría General Técnica de la Presidencia del Gobierno, no se pueden sustraer a la política de perfeccionar y modernizar la organización y funcionamiento de la Administración. Se trataba de la Ley de Régimen Jurídico de las Entidades Estatales Autónomas y de la de Tasas y Exacciones Parafiscales. Ambas auspiciadas por el Ministerio de Hacienda.

Su titular, Mariano Navarro Rubio, hizo la presentación de ambos textos junto con los de otros tres proyectos de Ley (de entidades oficiales de crédito a medio y largo plazo; de modificación de algunos preceptos reguladores de determinados impuestos; y de régimen jurídico y fiscal de las sociedades de inversión mobiliaria) en la Sesión Plenaria de las Cortes Españolas de 22 de diciembre.

López Rodó ha reclamado la coautoría de la Ley de Entidades Estatales Autónomas, pero nada ha dicho respecto de su participación en la de Tasas y Exacciones Parafiscales ${ }^{60}$. Se limita a señalar que venía impuesta por la Ley de Régimen Jurídico de la Administración del Estado cuando prohíbe imponer exacciones y cargas similares mediante disposiciones administrativas, y a despachar su contenido en diez líneas a pie de página.

Navarro Rubio pronunció un discurso eminentemente técnico, como correspondía a su calificación de tal dentro del régimen, en el que habló de la gestión presupuestaria, del equilibrio y saneamiento financiero, de la estabilidad económi$\mathrm{ca}$, de la Banca española, de las relaciones del Gobierno con las instituciones de crédito... En fin, de cualquier cosa menos del contenido de los cinco proyectos de Ley que estaba teóricamente presentando. Hizo algo similar a lo que Carrero Blanco había hecho cuando compareció el año anterior para explicar el proyecto de Ley de Régimen Jurídico de la Administración del Estado: si en aquella oportunidad Carrero se había limitado a exponer su pensamiento político, Navarro Rubio estaba explicando a un auditorio poco acostumbrado a que le hablaran de economía, lo que estaba siendo su programa al frente del Ministerio de Hacienda y sus ideas y propósitos para reformar la economía española.

Las cinco Leyes fueron aprobadas en un solo acto, como era la costumbre en las Cortes Españolas, con la unanimidad de los procuradores presentes $y$, encima, por asentimento.

\section{Fin de una década e inicio de otra itiempo de interludio administrativo, de crisis de crecimiento o de desencanto?}

El ritmo casi frenético que inicialmente se imprimió a la producción de nuevas leyes administrativas necesariamente tenía que decaer. El filón ya no daba más de sí. La necesidad de regular legislativamente los dos primeros aspectos de la reforma administrativa, el orgánico y el funcional —salvo en lo relativo a otras materias que pudieran rozar con lo presupuestario (contratación, patrimonio...), teniendo en cuenta la vis atractiva que entonces disfrutaba-, prácticamente se había agotado.

Por ello el año 1959 no trajo novedad alguna desde una perspectiva legislativa en el ámbito de la reforma administrativa. Desarrollar y aplicar la reciente Ley de Procedimiento Administrativo, iniciar la clasificación de todas las entidades estatales autónomas que constituían una inabarcable galaxia administrativa, y ordenar financieramente el régimen de las tasas y otras exacciones fiscales que recaudaban los servicios centrales y periféricos de los Ministerios para completar la insuficiencia de los créditos presupuestarios - sobre todo en los capítulos relativos a personal y a gastos ordinarios de funcionamiento de los servicios- era carga de trabajo suficiente para ocupar la agenda de los órganos con competencias directas o tangenciales en materia de reforma administrativa.

Pero había razones más importantes para ralentizar la marcha de ésta. Razones de índole política y económica.

En cuanto a las primeras, el propio López Rodó recuerda que en junio de 1957 se había creado una Comisión Delegada del Gobierno para el estudio de las Leyes Fundamentales ${ }^{61}$, y que uno de sus principales frutos fue la Ley de Principios del Movimiento Nacional. Al año escaso fue leída íntegramente por el Jefe del Estado en la Sesión Plenaria de las Cortes Españolas, de 17 de mayo de $1958^{62}$, a modo de enfática proclamación y consciente de su responsabilidad ante Dios y ante la Historia. Pues bien, en el Principio VII se declaraba que la forma políica del Estado Nacional era la Monarquía tradicional, católica, social y representativa, con una serie de cautelas y salvaguardas. Como ha contado LÓPEZ RODO en sus Memorias pero con más intensidad y especificidad en La larga marcha bacia la Monarquia, es a partir de ese momento cuando inicia con mayor de- 
dicación y entusiasmo su actividad para lograr la restauración de la Monarquía española ${ }^{63}$.

Por otra parte, y en cuanto a las razones económicas que hicieron que lópez Rodó distrajera su atención de la reforma administrativa, ya en marzo de 1959 se había aprobado por el Cobierno el primer Programa Nacional de Ordenación de las Inversiones Públicals. Y en el mes de julio del mismo año un importante y necesario Plan de Estabilización, que llevaban gestando descle el otoño anterior los Ministros de Hacienda y Comercio, Navarro Rubio y Ullastres, auspiciado por las autoridades del Banco Mundial y del Fondo Monetario Internacional, y bajo la supervisión de la O.C.D.E. El Plan de Estabilización em básico para la modernización de la economía española, pero suponía dar un giro radical a la política económica del régimen. Lo que inevitablemente produjo nuevas tensiones internas entre el sector tecnocrático del Cobierno y quienes seguían delendiendo una política autárquica e intervencionista, tal y como se había estado realizando descle 1939. Los altos costes sociales que suponía un duro Plan de Estabilización serían soportados, principalmente, por la clase trabajadora. Esto facilitó que el sector falangista del régimen arremetiera duramente contra los tecnócratas emergentes, que ahora se habían convertido en el principal impedimento para llevar a cabo la aún pendiente revolución social. Además, la austeridad y control del gasto público que el Plan de Estabilización implicaba era una fuente añadida de agrias discusiones en el seno del Cobierno.

El momento era políticamente muy delicado pues aunque el Jefe del Estado había dado luz verde al cambio de rumbo de la política económica, sin embargo mantenía no pocos recelos. Sobre todo de la sinceridad y eficacia de la ayuda y colaboración proveniente de organismos internacionales, a los que seguía considerando como refugios de la masonería internacional.

Navarro Rubio ha manifestado "

-...Franco no tenía, en un principio, la menor confianza en el Plan de Estabilización... Dudaba de la buena disposición para con nosotros de los organismos internacionales - hacia los que mostraba claros recelos- y temía nos quedásemos a merced de unos acreedores exteriores que no dudarían en colocarnos en una situacićn crítica, si las cosas no salían como habiamos pensado.

Con las preocupaciones inherentes a la implantación de un nuevo modelo económico más propio de una economía de mercado y su integración en el sistema capitalista internacional, así como la atención puesta en los movimientos políticos internos de otras fuerzas colaboradoras o periféricas del régimen, no es de extrañar que lópez Rodó careciera de tiempo y energía suficientes para dedicarse con el ímpetu inicial a otros temas menores de la reforma administrativa. Reforma que, salvo el prometido nuevo Estatuto de Funcionarios, ya había cumplido prácticamente el calendario legislativo que se había programado.

Pero la falta de atención a estas cuestiones también tenía otras causas. La agenda de viajes al exterior del Secretario General Técnico fue intensa, como se desprende del capítulo de sus Mernorias dedicado al año 1959: viaje a los Estados Unidos invitado por el Departamento de Estado, del 18 de abril al 13 de mayo; conferencia en el Royal Institute of Public Administration, de Londres, la última semana del mes de agosto; asistencia al Congreso en Wiesbaden del Instituto Internacional de Ciencias Administrativas; la inauguración del Centro de Formación y Perfeccionamiento de Funcionarios de Alcalá de Henares, auténtica joya de la corona para López Rodó... Al margen de otras actividades tan dispares como puedan ser las derivadas de la aprobación de varios decretos, entre el mes de septiembre y noviembre, suprimiendo nueve organismos de intervención económica (la Junta Superior de Precios, la Fiscalía de Tasas, los Servicios de la Madera o del Esparto, la Comisión para la fijación del precio del oro y de la plata... $)^{65}$, o las relacionadas con la visita del Presidente Eisenhower a final de aquel año.

Las múltiples ocupaciones que iba asumiendo el líder de la reforma administrativa y su atención prioritaria a otros objetivos políticos y económicos, fueron sin duda unas de las causas principales de que aquel movimiento empezara a perder su empuje, decayera el interés de los funcionarios que habian asumido el papel de vanguardias en el ámbito de los principales Ministerios ${ }^{66}$, y surgieran las primeras voces de autocrítica en relación con el sesgo que todos estos acontecimientos imponían a la reforma administrativa.

\section{a) Las primeras manifestaciones públicas de desaliento}

Curiosamente es en Docilmentación Administrativa, considerado como órgano oficial de la reforma administrativa desde su aparición en enero de 1958, donde empiezan a escucharse algunas voces que cuestionan la marcha del proceso. $Y$ son voces bastante cualificadas, como la de Antonio Carro Martínez, letrado del Consejo de Estado y profesor adjunto de Derecho político de la Universidad Complutense, pero sobre todo, Jefe del Gabinete de Estudios para la Reforma Administrativa y colaborador directo de López Rodó desde los primeros momentos. Y también, aunque desde una posición externa a la Presidencia del Gobierno, la de Manuel Pérez Olea, funcionario destacado del recién creado Ministerio de la Vivienda, que además procedía del ámbito del Instituto de Estudios Políicos.

En los números 27 y 28, correspondientes a los meses de marzo y abril de 1960, CarRo Martínez publica sendos artículos titulados ¿Qué es la reforma administrativa? y :La reforma administrativa en España. 
El primero es un articulo aparentemente pedagógico, en el que se pretende - con palabras del propio autor - rmatizar a la reforma administrativa desde un punto de vista negativo; es decir, partir de lo que no es para averiguar lo que es.. Pero de la lectura enseguida se percibe que tiene mayor calado y otras posibles intenciones.

Carro Martínez, de entrada, efectúa cuatro proposiciones con las que pretende situar en una posición claramente conservadora al movimiento de reforma administrativa, con la probable intención de no alarmar al régimen. 0 , más concretamente, a sus sectores más inmovilistas. Sus propuestas eran las siguientes: la reforma administrativa no es un proceso que pueda actuar por vía revolucionaria; la reforma administrativa no es la reforma política; la actuación política no es la reforma administrativa; $y$, por último, la reforma administrativa es la técnica del rendimiento.

El autor opta expresamente por esta última posición a la que, a pesar de la extraordinaria simplificación que suponía en su formulación literal, no tiene rubor en calificar como sa verdadera. Y que, por ello, supedita, mediante un curioso sofisma, al bien común, en el caso de contraposición de intereses. Para CARRO, el bien común es unna idea clásica, cargada de resonancias escolásticas.

Esta idea de sustraer la reforma administrativa de todo contagio político y reservarla sólo para los expertos y especialistas es expuesta recurrentemente por CaRro en su primer artículo. Como lo es también la de que en caso de conflicto de intereses debe prevalecer siempre el bien común. Coherentemente con este planteamiento propugna una reforma administrativa dirigida exclusivamente a las cosas pequenas. Lo que de entrada suponía un cambio radical en el enfoque que había tenido hasta ese momento. Su argumentación salta del espontaneísmo enternecedor al arbitrismo pseudocientífico:

-...pero el mejor sistema para evitar colisiones de este tipo Ise está refiriendo a las posibles colisiones con lo que llama el fin políticol consiste en evitar planteamientos de reformas de estructuras, y concentrar toda la potencialidad reformadora en métodos, detalles y minucias. Es evidente que el efecto multiplicador de las reformas de detalle produce a la larga unos resultados tanto o más positivos que las reformas de principios o estructuras. En definitiva, no se tema comenzar por aplicar la técnica del rendimiento a las cuestiones de detalle $\rightarrow$ la pequeña reforma. de los impresos, por ejemplo-, pues son de fácil aceptación, no producen fricción política y abocan necesariamente a tener que aplicar también la técnica del rendimiento a las cuestiones de principios $\rightarrow$ la gran reforma. de las estructuras $\longrightarrow$.

Además de este planteamiento (que suscrito por quien desempenaba la Jefatura del Gabinete de Estudios de la Reforma Administrativa necesariamente tenía que dar la impresión de que estaba a punto de estallar un cisma en el seno interno del núcleo principal del mismo movimiento), CARRo MarTíneZ dejó escritas unas cuantas frases que fácilmente podian interpretarse como una alusión directa a la actitud y temperamento de López Rodó, y una crítica velada a cómo se había instrumentado la reforma administrativa hasta aquel momento.

"La reforma administrativa debe ser ambiciosa en su concepción, pero sosegada en su implantación... Quien intente conseguir de golpe la eliminación de todas las corruptelas administrativas mediante la sustitución del orden administrativo tradicional por otro nuevo más racional y perfecto -lo que precisará la alteración de la división territorial, la supresión de todos los organismos inútiles, establecer nuevos criterios de desconcentración, desconocer situaciones y derechos adquiridos, etc. - necesitará estar revestido de una potencialidad política de carácter fundamental. Este rompimiento o trastocamiento violento de un orden administrativo existente sólo puede actuarse mediante poderes de naturaleza política no administrativa y mítica no ordinaria. Pero en este caso excepcional no se habría producido una reforma administrativa, sino una revolución administrativa... la racionalización de un orden administrativo es más bien una conveniencia que un estado de necesidad... la reforma administrativa verdaderamente fructífera no suele ser la más espectacular... la reforma administrativa es en la actualidad una bandera lo suficientemente atractiva para que sea concebida como nueva vía de acceso y utilización del poder político... cabe reformar la Administración sin gran aparato de leyes $u$ otras disposiciones jurídicas generales... los políticos predispuestos a favor de la reforma administrativa pueden ayudarla; no obstante, también hay muchos políticos menos bien dispuestos....

En fin, un buen muestrario de consejos y advertencias expuestos con una cierta rudeza, que lógicamente no debieron entusiasmar a López Rodó. Y mucho menos que se los hiciera un subordinado jerárquico y desde la propia revista de la Secretaría General Técnica. Nunca ha sido un buen síntoma de salud de un organismo público que alguien que depende de uno se tenga que comunicar a través de un medio público.

Algún rapapolvo debió recibir el autor por hacer públicas sus discrepancias con el líder indiscutible ( $y$, al parecer, también indiscutido) de la reforma administrativa y de una manera tan tosca, pues en el número del mes siguiente, correspondiente a abril, apareció un nuevo artículo de Antonio CarRo que se movía entre la necesidad de matizar algunas de las cuestiones apuntadas en el anterior, aunque no se dijera expresamente, y la rectificación más ostentosa y casi humillante.

Se trata de un artículo menos conceptual que el anterior, en el que se describen en tono laudatorio las realizaciones llevadas a cabo hasta ese momento, llegando a afirmar con rotundidad, 
elogiosa en exceso, que ala instrumentación jurídica de la reforma administrativa es magnífica. En boca de quien había mantenido algo diferente hacía un mes era, cuando menos, poco pudoroso.

Pero para no dar del todo su brazo a torcer, CarRo Martínez termina el trabajo distinguiendo el procedimiento de la gran reforma del de las pequeñas reformas. El primero, de una simplicidad sorprendente, consistia para el autor, ni más ni menos, en la constitución de un grupo de expertos que detectaran los problemas orgánicos y de procedimientos existentes en cada Ministerio.

-Luego sería de sumo interés que los jefes de estos servicios, en mesa redonda, deliberaran acerca de la problemática planteada a fin de coordinar criterios. En este punto sería indispensable que, frente a los intereses de clase, estructura o Departamento, prevaleciera exclusivamente el interés del rendimiento. Asi sería posible desembocar en un programa general de reforma administrativa que debería ser sometido a la aprobación del Consejo de Ministros.

En cuanto al segundo, la reforma de los procedimientos, el planteamiento es aún más sorprendente, pues se limitó a decir que

.el procedimiento es mucho más sencillo porque no se precisa coordinación ni sacrificar las posiciones más preciadas de los diversos sectores administrativos. Se puede comenzar por reformar las cuestiones de detalle de menor importancia y poco a poco, a fuerza de minucias y detalles, empezará a vislumbrarse una gran reforma hecha a base de muchas pequeñas reformas.

En definitiva, milagrero, visionario y voluntarista.

Por eso no es de extrañar que en el mes de octubre siguiente, Antonio Carro Martínez recibiera un desplazamiento colateral con ascenso. La recién creada Secretaría General Técnica del Ministerio de la Gobernación, inexistente hasta ese mismo mes, fue la oportunidad de oro para ascender y enviar al primer disidente de la Secretaría General Técnica de la Presidencia del Gobierno, a la vera del general Alonso Vega, entonces Ministro del ramo ${ }^{67}$.

Todavía en el número siguiente de Documentación Administrativa, el $n^{2} 29$ de mayo de 1960, hay una nueva incursión teórico-práctica sobre la noción de la reforma administrativa. Manuel PÉREz OLEA echa su cuarto a espadas con un artículo titulado «a continuidad de la reforma administrativa. De entrada hacia una reflexión conceptual sobre los dos tipos de reformas administrativas, la estructural y la procedimiental, para pasar revista a continuación, de una manera descriptiva y aséptica, a las principales medidas ya adoptadas en ambos aspectos desde la creación de la Secretaría General Técnica de la Presidencia.
Pero lo más importante venía en la última parte del artículo, que ajustaba su contenido al enunciado del título.

La intención de PÉrEz OlEa era situar la reforma en sus justos límites, pero sobre todo hacer un llamamiento a la necesaria continuidad para recuperar las adhesiones iniciales perdidas y evitar nuevas deserciones, principalmente entre los propios funcionarios.

-La reforma administrativa española se encuentra ahora en el momento crítico de dar efectividad en toda su extensión a lo que sobre el papel figura ya establecido. Es tal vez el paso más difícil y en el que se hace más preciso insistir en la necesidad de configurar la reforma administrativa como un proceso continuo. La reforma administrativa ha envejecido como slogan, como tema de actualidad, y no falta quien considera que, cumplida ya la etapa más brillante y vigentes textos de tanto valor como la Ley de Procedimiento, es ocioso insistir en algo que va perdiendo ímpetu por un proceso natural de desgaste.

PÉREZ OlEa justifica el desencanto de algunos sectores que desde dentro de la Administración récibieron ilusionados la reforma, ante los magros resultados que eno justifican el bullicio inicial. Y recuerda que el proceso es cuestión de tiempo y perseverancia. Por supuesto que es más fácil! por desgracia, promulgar un gran texto legislativo que imbuir de su espíritu a una maquinaria sumida en la rutina y en la pasividad de lustros. Pero por eso hay que luchar contra el mayor enemigo de la reforma: el desaliento y la indiferencia por parte de quienes iban a ser los más directos beneficiarios. Según sus propias palabras, éstos eran los gobernantes, funcionarios y administrados.

\section{b) La irresistible ascensión de López Rodó}

Por Decreto 102/1962, de 1 de febrero, Laureano López Rodó es nombrado Comisario del Plan de Desarrollo Económico (el añadido de lo social. vendría meses después ${ }^{68}$, impuesto por las quejas y críticas provenientes de la Organización Sindical). Supone un ascenso en su carrera política ya que, con arreglo a otro Decreto de la misma fecha que crea el cargo y la organización aneja, se le ha otorgado la categoría y retribución de Subsecretario. Le sucede al frente de la Secretaría General Técnica, José María Hemández Sampelayo, inspector de Seguros y Ahorro, y por lo tanto de un cuerpo de funcionarios dependiente del Ministerio de Hacienda, que hasta ese momento había desempenado la Jefatura de la Oficina de Planes Provinciales, también dependiente del mismo centro directivo ${ }^{69}$.

Si bien Hernández Sampelayo asumió desde el primer momento la actitud de situar la actividad de la Secretaría General Técnica bajo el patronazgo y supervisión de López Rodó, su antiguo jefe, al que profesaba una lealtad sin reserva alguna, la 
realidad es que la marcha de éste hacia otras responsabilidades políicas más específicas fue determinante para que dejara de atender personalmente el rumbo del ya fatigado movimiento de la reforma administrativa ${ }^{70}$.

Durante los meses de marzo a junio de 1961 había estado en España una misión del Banco Internacional de Reconstrucción y Fomento (Banco Mundial). El objetivo básico de la misma era ayudar a la Administración española en la preparación de un plan de desarrollo econónico a largo plazo para la expansión y modemización de la economía y, por consiguiente, la elevación del nivel de vida del pueblo español ${ }^{71}$, al mismo tiempo que se mantenia la estabilidad financiera. La misión estaba compuesta por 17 miembros de siete países. Si bien el informe final fue remitido al Gobierno español en agosto de 1963, sus versiones preliminares ya apuntaban acerca de la necesidad de contar con una organización administrativa ad boc ${ }^{72}$.

De todas formas, la creación del cargo de Comisario del Plan de Desarrollo y el coincidente nombramiento de López Rodó, suscitaron esta vez algo más que recelos. Según ha contado el propio interesado ${ }^{73}$,

-mi nombramiento no estuvo libre de obstáculos. Hubo, en particular, dos ministros que supieron medir el alcance político y económico de la tarea que se me iba a confiar y trataron de asumirla ellos o, mejor dicho, de colocarla bajo su dependencia. Navarro Rubio quiso que la programación económica se hiciera desde el Ministerio de Hacienda y Solis pretendió que se encomendara a la Organización Sindical. Navarro Rubio llegó a hacer de ello cuestión de gabinete y, como él mismo ha escrito, presentó su dimisión por haberse creado la Comisaría del Plan de Desarrollo en la Presidencia del Gobierno y no en Hacienda. Solís, secundado por Cirilo Cánovas, Ministro de Agricultura, hizo todo lo posible en el Consejo de Ministros del 26 de enero por estorbar mi nombramiento proponiendo candidatos alternativos... en último término pidió Solís que el asunto quedara sobre el tapete.

La cuestión quedó zanjada, de momento, cuando Franco terminó por aceptar el nombre de López Rodó que proponía Carrero Blanco.

Uno de los mecanismos que introdujo el Decreto 94/1962, de 1 de febrero, de creación del cargo de Comisario del Plan de Desarrollo Económico, para reforzar aún más la posición institucional de López Rodó, fue la posibilidad de que asistiera a las reuniones de la Comisión Delegada de Asuntos Económicos. Lo que sucedia habitualmente ${ }^{7 \hbar}$.

Para la puesta en marcha de todo el tinglado organizativo de la flamante Comisaria del Plan de Desarrollo, como coloquialmente era conocida, López Rodó contaba de entrada con el apoyo del Cuerpo de Economistas del Estado. Éste se había creado por Ley de mayo de 1956, es decir, meses antes de su llegada a la Secretaría General Técnica de la Presidencia del Gobierno. Y la realidad es que cuando se creó la O.C.Y.P.E. en febrero del año siguiente, la mayor parte de los economistas se nuclearon, como era natural, en torno a este nuevo órgano, al que se ha considerado germen o embrión de la futura Comisaría del Plan. Y de aquélla pasaron a ésta. López Rodó consiguió en diciembre de 1962 un espectacular incremento del 50\% de la plantilla presupuestaria inicial ${ }^{75}$ del Cuerpo. Ya que, aunque no había sido su creador, desde el primer momento se convirtió en su entusiasta patrocinador y defensor de sus intereses. Los economistas del Estado manejaban unos conocimientos y unas técnicas de los que, salvo sus más directos rivales -los técnicos comerciales-, existía una gran insuficiencia en los Ministerios.

Mientras López Rodó se dedicaba a dar vida a las diecinueve Comisiones y seis Ponencias que inicialmente se habian constituido, integradas por funcionarios, especialistas, empresarios y sindicalistas, para la preparación del I Plan de Desarrollo Económico y ya también Social, Hernández Sampelayo retomaba como trabajo prioritario la elaboración del Estatuto de Funcionarios civiles del Estado.

Ya en abril de 1960 CARRO MARTínez $^{76}$, al hacer balance de lo que se habia realizado y de lo que aún faltaba por hacer en materia de reforma administrativa en España, había dicho:

"... auin queda algo por hacer en el aspecto jurídico-normativo. Se trata de la promulgación del nuevo Estatuto de Funcionarios, si bien cabe adelantar que, en este punto, se han venido haciendo, durante los últimos años, los estudios prelegislativos más serios y profundos de toda nuestra historia administrativa. Ahora bien, el problema se halla tan deformado en la realidad que es preciso un apoyo político de gran fortaleza y libre de influjos burocráticos.

Efectivamente, al parecer hacía tiempo que se le habia entregado a Carrero Blanco un ejemplar de lo redactado como nuevo Estatuto de Funcionarios. Y el Ministro, después de su atenta lectura, había escrito en la esquina superior de la portada la siguiente palabra: opio. Lo que significaba que el anteproyecto todavía debía dormir un largo rato ${ }^{n}$.

La lucha de los grandes cuerpos por la conquista o mantenimiento de espacios orgánicos y funcionales de la Administración como zonas de su exclusiva competencia, hacía tiempo que estaba patente ${ }^{78}$. Al Ministro Subsecretario de la Presidencia no le pareció oportuno en aquel momento abrir un nuevo frente de inquietud, esta vez nada menos que en là Administración estatal, que pudiera repercutir de manera negativa, aunque fuera indirectamente, en la tranquilidad interna del régimen. 


\section{A modo de epílogo}

En seis años transcurridos desde la creación de la Secretaría General 'Técnica de la Presidencia del Gobierno, el avance de la reforma administrativa en el plano legislativo y también desde la perspectiva del desarrollo organizacional había sido importante.

Se aprobaron unas Leyes de contenido administrativo que constituyeron el nuevo marco jurídico de referencia para la organización y el funcionamiento de la Administración del Estado.

\section{Y como comenta Beltrín VILLALBA ${ }^{71}$}

Una reforma de la Administración que se limitase a cambiar, o retocar, las leyes vigentes sería descle luego insuficiente; pero una reforma que las dejase sin tocar adolecería seguramente de igual limitación. Pues bien, el proceso de cambio que se acomete en la Administración española desde la segunda mitad de la década de los cincuenta reformó la legislación, incluso promulgando leyes nuevas que han gozado de una prolongada vigencia, e introdujo, con más o menos éxito, cambios orgánicos y operativos.

Es una buena síntesis de lo que sucedió en los primeros años de reforma administrativa. Pues además de las mencionadas leyes administrativas, se crearon en todos los Ministerios civiles unos nuevos órganos (las Secretarías Generales Técnicas) que facilitaban el apoyo a los objetivos generales de la reforma, a la par que procuraban racionalizar, en términos de mejora y perfeccionamiento, la actividad cotidiana, a medio y largo plazo, de los Ministerios ${ }^{*}$.

Bien es verdad que el tercer pilar de la reforma -la de personal- se había encontrado con mayores obstáculos y dificultades de los inicialmente previstos, y, en cierta manera, se había ralentizado tanto que parecía paralizada. Pero quedaban múltiples trabajos, estudios y borradores de anteproyectos que constituían una documentación importante y valiosa para el momento en que se tomara la decisión política de sacar adelante el nuevo Estatuto de Funcionarios.
La formación de un nuevo Gobierno en julio de 1962 podía suponer una nueva oportunidad para completar la reforma legislativa de la Administración. En principio, el reforzamiento gubernamental de los tecnócratas ${ }^{81}$, como primera valoración de la crisis, podía considerarse como un factor positivo para que la reforma administrativa pendiente cobrase un nuevo y decisivo impulso.

Así sucedió. En julio de 1963 se aprobaba la ley de Bases de Funcionarios civiles del Estado, que puede ser considerada desde la perspectiva del pasado más próximo, como un importante esfuerzo y la pieza normativa básica para la estructuración de la Función Pública española. Al margen de las vicisitudes que tuvo su posterior desarrollo y aplicación.

Como acaba de apuntarse, tanto la Ley de Régimen Jurídico de la Administración del Estado como la de Procedimiento Administrativo y el texto articulado de Funcionarios civiles, han sobrevivido hasta época muy reciente, después de casi cuarenta años de vigencia y aplicación.

Sería excesivamente simplista atribuir este dato sólo a la extraordinaria calidad técnica de estos textos. Por supuesto que han intervenido otros factores, principalmente políticos. Pero tampoco deberíamos olvidar que algunas modificaciones que se introdujeron en los años 1984 y 1992, parciales en un caso y más amplias y generales en la segunda ocasión, ni sirvieron para mejorar de manera relevante la calidad ni preparación técnica de los funcionarios españoles, ni para alcanzar mayores cotas de modernización de nuestra Función Pública, ni para conseguir logros significativos en materia de nuevas garantías administrativas para los ciudadanos. Ni tan siquiera para evitar en un caso la necesidad, ampliamente sentida desde el primer momento (como sucedió con la regulación del llamado procedimiento administrativo común), de proceder a su pronta modificación.

Pero todas éstas son cuestiones que bien pudieran abordarse en nuevos apuntes que sirvan para completar la intrahistoria de los recurrentes movimientos de reforma, cambio, transformación y modernización que se han preocupado de nuestra Administración durante las cuatro últimas décadas.

\footnotetext{
' MLN:NIDI:Z PIDNL. Historia de Espania Tomo XLI, III La Adıninistración, dirigido por Nigucl Belırín Villalba, Espasa Calpe 1996, pág. 599.

2 El propio Fi:kivisill:z. Culssin dio una explicación de aquella crisis en Franco tisto por sus minisıros, Planela 1981, píg. 20. Comenta su entrevista con el Jefe del Estado a la vuelta de un viaje a Brasil, y cuando pretende iniciar la versión de lo sucedido durinic su ausencia: .... Franco me contó la palabra diciéndome que no ruviera ninguma inquicud, porque habia resuelıo mi cese y' el del ministro de Educación, loaquin Ruiz Giménez, pero sin darme ninguna explicación por los morivos de su decisión.
}

Éstos no podian ser otros que el de poner lérmino a una politica en materia estudiantil y universitaria considerada equivocada por los dos ministros a quienes aquéllas correspondian. El de Educación, por estimular o amparar actiludes hostiles al Régimen, la Secretaria General, por no haber sabido o podido anularlas o contrarrestarlas.

" Ver Historia del franquismo, Planeta 1978, pág. 143.

4 En el libro antes citado de Franco visto por sus ministros, pág 61, Arrese puntualiza el significado que turo esıa inquietante expresión: •En realidad lo que fracasó no fue 
la conquista de la calle. sino el propósito de institucionalizar el régimen. La conquista de la calle era el procedimiento (que hoy llamariamos democrático.) para lograr la aquiescencia del pueblo en la necesidad de dar unas Leyes constitujentes al Estado y normas de sucesión en las tres Jefaruras (Estado, Gobiemo y Movimiento) que ostentaba el Caudillo. Lo que no deja de ser una interpretación benévola con efectos retroactivos. La conquista de la calle. era una expresión que en aquel momento tenía un claro significado: el de una consigna pam determinado tipo de acciones y movilizaciones.

5 Laureano LÓFEz. RODÓ en su libro Políica y Desarrollo, Aguilar 1970, al recordar la cojuntura politica de su llegada a la Secretaría General Técnica de la Presidencia del Gobiemo, se refiere concretamente a lo que Arrese dijo en la ciudad castellana. Y comenta: Arrese entró en la Secretaría General con nuevos bríos y mejores intenciones. Pronunció un importante discurso, con garra, en Valladolid, el 4 de marzo, aniversario de la fusión de Falange Española y de las JONS, y emprendió la nada fácil tarea de reanudar el proceso instirucional abierto el 18 de julio.

- José Luis Arrese en el libro antes citado Franco visto por sis ministros, pág. 53, se refiere al beneplácito que este discurso había recibido previamente de Franco: $\cdot$...le llevé el bormdor del discurso que pronunciaría el 4 de marzo en Valladolid ...me aprobó el anuncio de empezar el estudio de las leyes.... De todas formas conviene recordar que el propósito de completar la institucionalización del régimen con orras Lejes Fundamentales es una cuestión que venia de atrás. Ya en febrero de 1955 Franco autorizó al entonces Ministro Secretario General del Movimiento, Raimundo Fernández Cuesta, para que redactara leyes que cerraran los resquicios que pudiera laber en la Ley de Sucesión e irrevocablemente ataran al sucesor real al Movimiento. En este sentido, ver Paul Prlsion, Franco, calldillo de Esparia, Mondadori 1994, pág. 795.

7 Ob. cit. paig. 149.

${ }^{8}$ Ver Laureano Lóprz Rodó, Memorias, Plaza \& Janés y Cambio 16, págs. 51 y 52.

9 Stanley PAYne, Franco y José Antonio. El extrario caso del fascismo español, Planeta 1997, pág. 627. Para llegar a montar esta interpretación se basa en las memorias del propio ARRESE, Una etapa constituyente 1982.

${ }^{10}$ Ver la obm de Laureano Lópz Royó citada en nota 7, pág. 641.

"El contenido de esta entrevista lo cuenta Lom:z. Ronó en la obra antes citada, pág. 75, citando como fuente de la misma al cardenal Quiroga, Arzobispo de Santiago de Compostela, de cuya Universidad habia sido catedrático. También ver Stanley PaYN:, ob. cii., pág. 628.

12 Rafael Calvo St:ki:R, Franco frente al Rey, Ruedo Ibérico 1972, pág. 87.

1. Ver ob. cit., págs. 628-630. Asimismo, este autor da cuenta de la obsesión de Artese por la escasa participación de la Falange en las organizaciones políticas y entidades püblicas dependientes del régimen. El 29 diciembre de 1956, cuando ya se podia considemr que sus proyectos de leyes fundamentales habian fracasado, en su informe ante el Consejo Nacional del Movimiento expuso unos datos tendentes a demostrar que en la esiructura politica española, los camisas viejas. del partido no tenian más que la siguiente representación en todo el Gobierno del Estado: 2 de 19 ministros; 1 de 17 subsecterarios; 8 de 102 directores generales; 18 de 50 gobernadores civiles; 8 de 50 alcaldes de capitales de provincia; 6 de 50 presidentes de Diputaciones; 65 de 151 consejeros nacionales; 137 de 575 procuradores en Cortes; 776 de 9.155 alcaldes; y 2.226 de 55.960 concejales. Es decir -comentaba Arrese-, que la Falange primitiva ocupa aproximadamente el $5 \%$ de todos los puestos de mando y representación de España.

if Javier Tusell, Camrero. La eminencia gris del régimen de Franco, Temas de Hoy 1993, pág. 230.

"Ob. cit., pág. 151.

${ }^{16}$ Ob. cit., pág. 62.

${ }^{17}$ En el Comité de Organización del Congreso, además de Gascón y Marín figuraban los eximios administrativistas Jordana de Pozas y Royo-Villanova, y como representantes cualificados de las jóvenes generaciones, López Rodó y García de Entería. Ver la crónica de este X Congreso en la Rerista de Administración Priblica $n^{\circ} 27$, págs. 291-294.

${ }^{18}$ Alejandro Nilio en Apuntes para una bistoria de los autores de Derecbo Administratit:o general español, INAP 1983, pág. 62, hace una semblanza de Gascón y Marín a quien considera que fue durante treinta años el patriarca y cacique del Derecho Administrativo español. También recuerda que en el escalafón universitario fue el primer caredrático que explicó Derecho Administrativo exclusivamente, como consecuencia del desdoblamiento de la cátedma tmadicional de Derecho político y administrativo.

${ }^{19}$ Los otros dos temas del Congreso fueron: Los contmitos para la ejecución de obras públicas y .Tendencias actuales para el perfeccionamiento de los cuadros superiores de la Administración.

${ }^{2}$ Ob. cit., pág. 62.

${ }^{21}$ Ob. cit., pág. 64.

"2 Por ejemplo, dijo al comienzo: .La reforma de la Administración pública estriba en lograr infundir, sobre lo que es estabilidad y autoridad, el soplo de la vida.

24 El articulo 11 del Decteto-ley de 25 de febrero de 1957, sobre reorganización de la Administración Central del Estado, creó el Ministerio de la Vivienda. Lo que permitió sacar a José Luis Arrese de la Secretaría General del Movimiento y nombrarle titular del nuevo Departamento ministerial. Según dijo Franco a Carrero no conviene que salga ahora con la bandera de sus Lejes Fundamentales. Necesito que se enfrie antes en el Ministerio de la Vivienda. Ver Paul Priston, ob. cit., pág. 830. Efectivamente, Arrese abandonó definitivamente el Gobiemo en la siguiente crisis ministerial de 1962.

${ }^{24}$ LOPEZ RODÓ se muestra aqui más pragmático que teórico de la reforma administrativa. O mejor dicho, con unos claros planteamientos tácticos para el ejercicio del poder en la Administración. En otro momento de su conferencia insistió en la conveniencia de contar con órganos para el análisis de los presupuestos con vistas a dicha reforma. Y llegó a afimmar: -los presupuestos son el anma decisiva de toda reforma. Lo que, además de ser obvio, seria más tarde uno de los morivos de frecuentes fricciones y de confrontación entre el Ministerio de Hacienda y la Presidencia del Gobiemo, que llegaron a su cenit en febrero de 1962 cuando se creó la Comisaria del Plan de Desarrollo Económico. En este orden de cosas, no estará de más recordar que en los PGE para el bienio 1958-59 se cifró un crédito de mil millones de pesetas para financiar obras y servicios de carácter eminentemente provincial o local. Pues bien, la Comisión Interministerial de Planes Provinciales, encargada de proponer la distribución del crédito, estaba presidida precisamente por el Secretario General Técnico de la Presidencia. Aunque esta función poco tuviera que ver con la refomia administrativa, enseguida se constituyó una oficina bajo la inmediata dependencia jerárquica de lópez Rodó para llevar a cabo toda la actividad administrativa relacio. nada con la distribución de los mil millones de pesetas. Lo que innegablemente facilitaba una projección politica del Secretario General Técnico en las cincuenta provincias españolas. Ricardo DE LA CII:RVA, ob. cit., pág. 175, considera a los planes provinciales un nuevo e importante centro de poder de los tecnócratas, desde cuya sede captaban a toda la red de administración local y creaban una tupida malla de influencia.

x Luis JORI)ANi DE: POZ,as también habia sido ponente en el X Congreso Intemacional de Ciencias Administrativas, precisamente con un trabajo titulado -Las Comisiones para la reforma administrativa., publicado en el $n^{2} 27$ de la Revista de Administración Priblica, págs. 215-221.

*6 Esta referencia no pudo resultar más oportuna. Quienes disfrutaban de acceso restringido a los entresijos del régimen sabian que entonces existian profundas divisiones y enfrentanientos entre los Ministros de Franco. Francisco Franco Sillsillo-Araujo en Mis comersaciones privadas con Franco, Planeta 1976, pág. 159, en una anotación correspondiente al 27 de enero de 1956, comenta que el Ministro de Trabajo, el falangista José Antonio Girón de Velasco, le había reconocido que el Gobiemo está gastado y dividido.

27 Esta nota, según cuenta LÓPE Rodó en sus Mermorias, pág. 68, se la remitió al Ministro de Justicia con carta de 15 de noviembre, en la que le decia: . Tengo el gusio de acompanarle la nota sobre la reforma administrativa que usted me pidió ayer... Me alegra ver que la idea de la reforma administrativa se abre camino. Mucho le deberá a usted, señor Ministro, la Administración española y los administrados por haber acogido, desde el primer momento, con entusiasmo, la iniciativa y haberla hecho viable. El Ministro de Justicia, a su vez, envía la nota a Carrero Blanco con carta particular de 28 de noviembre; esto es, trece dias después. En ella le comentaba. sobre este interesante problema consulté con Su Excelencia, quien me indicó que te la remitiem a ti. Le vi muy interesado en este trascendental problema que la Administración espanola tiene planteado. Es necesario que la idea de la reforma administrativa se abm camino. (curiosamiente utiliza la misma expresión que lo habia hecho López Rodó unos dias antes). Y iermina la cara recomendando a López Rodó para la cuestión: $\cdot E l$ Sr. López Rodó, que es un hombre muy aprovechable y que ruvo a su cargo la Ponencia de la reforma administrativa en el último Congreso de Ciencias Administrati- 
vas, podrí completar cuanto precises la nota que yo te adjunto. Esta última carta del Ministro de Justicia y la nota aneja figuran en el Archivo de la Presidencia del Gobierno. Legajo 105. Oficialia Mayor. 4714/4.

${ }^{28}$ Entonces existían Secretarias Genemles Técnicas en cinco Ministerios: Educación Nacionnl, Industria, Comercio, Agricultum, e Información y Turismo.

* Se han cscrito otras versiones sobre el origen de las relaciones de Camero Blanco con Lol'li:. Ronó, que han sido calificada de fábulas disparatadas. por éste. En este sentido, ver sus Memorias, pág. 67. Entre ellas, la que tuvo mayor difusión apareció en el libro colectivo escrito bajo el seudónimo de lesús YNianT:, La prodigiosa aienIura del Opus Dei, Ruedo lbérico 1970, págs. 177 y 178, y que, sin mayores comprobaciones, ha sido el origen de todas las posteriores. Luego reproducido en Comrersaciones con Fabión Estapé, Universidad Autónoma de Barcelona 1989, pág. 127, entre orms publicaciones. Se refiere al hecho de que, al parecer, Carrero Blanco labia acudido pam resolver un problema familiar al bufete que Amadeo de Fuenmajor, carcdrático de Derecho Civil y sacerdore del Opus Dei, compartia con López Rodó. Éste, por orm parte, ha recordado que conoció incidentalmente al Ministro Subsecretario en una visita a la Escuela Naval de Marin, encontrándose él alli para ver a un hijo suyo guardiannarina -los intercambios de la Universidad y la Escuela $\mathrm{Na}$ val enn muy frecuentes, ver pág. 66 de sus Memorias. Las versiones pueden ser perfectamente compatibles. No tiene nada de extraño que si lópez Rodó hubiera conocido a Carrero a tavés de su actividad profesional como abogado, tal y como se apunta en el libro de lesús YNFantr, resulta bastante lógico que mantenga una reservo o discreción sobre el asunto por un elemental y plausible principio de ética. O si se prefiere, de acuerdo con las elementales normas deontológicas aplicables al ejercicio de la abogacía. De todas formas, también pone en tela de juicio la versión de Jesús YNilinIl:, Javier Tusi:Ll, ob. cit., págs. 272-274. En el programa •La clave de la 2 de TVE del día 28 de enero de 1999, José Luis Balbín entrevisto a López Rodó. Le preguntó por el origen de su relación con Carrero Blanco, apuntando la versión de la crisis familiar de éste. López Rodó estuvo tajante al calificarla de •patrana total., insistiendo de forma contundente, patrnna al ciento por cien, incluso al mil por cien.

* Figura también en el Arclivo de la Presidencia del Gobierno, en el legajo citado en nota 23.

"Lorli:. Rons, ob. cit., pág. 68. Con el tiempo el Oficial Mayor de la Presidencia fue nombmdo primer Vicepresidente de la Comisión Superior de Personal. Esto ocurtió en julio de 1963. Conviene retener este dato.

* Arículo $3^{\circ}$ del Decrelo-Ley de 20 de diciembre de 1956 (BOE del día 22).

"El articulo $4^{2}$ del borrador que llegó a la mesa del Consejo de Ministros, decía asi: - A partir de la publicación del presente Decrelo-Ley, todas las disposiciones, que liayan de dicarse, que contengan alguna modificación en la organización administrati'a, tanto en cuanto se refieren a normas orgánicas o de procedimiento, como en las relativas a personal, requerirán para su aprobación el informe de esta Secretaria Geneml Técnica, que, de producirse en disconformidad con el proyecio sometido a estuclio, exigirá la expresa aprobación del mismo por el Consejo de Ministros.

"Más larde la idea reapareció mucho más elaborada y confiriendo la competencia de aprobación de las disposiciones de carácter general referidas a estas materias a la Presidencia del Gobierno, en el anticulo 130.2 de la Ley de Procedimiento Administrativo, de 17 de julio de 1958.

"En Memorias, pág. 69.

.6 Ob. cit., pág. 69. Esta misma idea aparece también expuesta por javier Tusi:LL, ob. cit., pŕg. 235: .Presidencia, antes de 1957, no em prácticamente nada, ni siquiera desde el punto de vista fisico, El propio Boletín Oficial del Estado dependia del Ministerio de la Gobernación, y los funcionarios del palacete de Castellana, 3 eran escasos y imnsmitian un aroma verusto: el oficial mayor, que era la máxima autoridad, era hijo de quien había desempeñado idéntico cargo en la época de la República. Con el imnscurso del tiempo, no obstante, Presidencia se convertiria en un centro de poder decisivo con responsabilidades muy amplias.

"Archivo de la Presidencia del Gobiemo, Legajo 4717/4 de la Oficialía Mayor, antes cilado.

- El que fue Ministro de Comercio, Alberto Ullastres, ha dado la siguiente explicación a la denominación de tecnócratas: • Yo creo que lo de tecnócratas vino de la imposibilidad de etiqueamos políticamente. No perteneciamos a las familias indicionales del Régimen: no éramos falangistas, ni democristianos, ni tradicionalistas. Eminos servidores del Estado y tenía una cierta máón de llamamos asi. Habiamos sido llamados porque los políicos no entendian de economía, que entonces em una ciencia prícticamente nueva en España y nos llamaron a los técnicos; concretamente a mí que me consideraba y considero un técnico. A algunos políticos les molestó bastante... Causé cierto escándalo cuando en los actos públicos nunca me puse la camisa azul ni el uniforme de Ministro que entonces era usual. Iba siempre de chaqué y llamaba mucho la atención porque destacaba o me diferenciaba ostensiblemente del resto de mis compañeros. Entrevista de Joaquin BaRDavio en Historia del franquismo, Diario 16, págs. 471-474.

* LOPE. Ronó, ob. cit., pág. 96 , comenta que no fue un simple relevo de guardia. de la siguiente manera: Ultimada la lista del nuevo Gobiemo y firmados por Franco los Decretos de nombramiento de los Ministros, Carrero llamó a su despacho a Arias Salgado. A mi me llamó también para que explicara al Ministro de Información el alcance de la reforma. Tan pronto Carrero entregó la lisia del nuevo Gobiemo a Arias Salgado, éste le dijo: Muy bien, ahora mismo ordenaré su difusión y haré que mañana publiquen los periódicos, como otras veces, un editorial sobre el relevo de la guardia. Carrero le atajó: -No se tmata de un simple relevo; se reorganiza la Adminisimación Central. López Rodó te explicará su alcance y te entregará incluso unos gráficos ilustrativos. Por su parte, Paul PRlsion, ob. cit., pág. 828, afirma: -La reestructumación del gabinete de febrero de 1957 iba a ser una de las más grandes líneas divisorias en la carrera políica de Franco. Marcó su iransición de políico activo a figura simbólica.

\section{Ob. cit., pág. 86.}

"Ver Jesús YNFantr:, ob. cit., págs. 315-316, en la que considera al Instituto de Estudios Políticos como centro de la alta cultura del régimen franquistar, y también se refiere a ta amplitud mental de estos intelecruales.

${ }^{12}$ El consejo de redacción estaba integrado por Luis Jordana de Pozas, jefe de la sección de Administración pública del Instituto y catedrático de la Universidad de Madrid; Manuel Alonso Olea, letrado del Consejo de Estado; Juan Ignacio Bermejo Gironés, jefe de Estudios Municipales del Ajuntamiento de Madrid; Eduardo García de Enterria, letrado del Consejo de Estado; Fernando Garrido Falla, profesor adjunto de la Universidad de Madrid; Juan Gascón Hernández, letrado de las Cortes; Segismundo Royo-Villanova, catedrático de la Universidad de Madrid; Femando Sáinz de Bujanda, profesor adjunto de la Universidad de Madrid; y José Luis Villar Palasi, letmdo del Consejo de Estado.

43 Ver su articulo -Crónica de los cien primeros números de la Revista de Administración Pública. publicada en 34 articulos seleccionados de la Revish de Administración Priblica con ocasión de su centenario, INAP 1983, págs. 69-75.

${ }^{48}$ Precisamente fue Documentación Administrativa, revista editada por la Secretaria General Técnica de la Presidencia del Gobierno y el Centro de Formación y: Perfeccionamiento de Funcionarios de Alcalá de Henares a partir de enero de 1958, la que llenó el vacio existente entonces en nuestro país, de una revista dedicada a los aspeclos no juńdicos de la Administración Pública o si se prefiere a la Ciencia de la Administración. Su finalidad no podia estar más clara: informar y facilitar documentación sobre la reforma administrativa y crear un clima favorable, asi como difundir en la sociedad española la preocupación por los problemas administrativos. Y todo ello sin pretender dogmatizar ni emplear un lenguaje ex catedra. El sumario del número 1 no podia ser más expresivo de estos propósitos y de las vías por las que iba a transitar

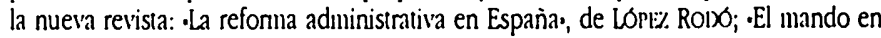

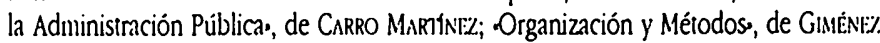
ARRIIBA; $y$ •Normalización de tamaños de papel en documentos e impresoso, de $\mathrm{CA}_{\text {- }}$ SALS MARCín. También contaba con orras secciones, tales como Crónicas, Notas Informativas, Noticiario de actualidad, Comunicaciones e iniciativas y Documentación bibliográfica. En una nota informativa, y bajo el titulillo de -Biología del Consejo de Ministros, se daba cuenta de un articulo publicado en The Economist (Parkinson esrudia el Consejo de Ministros), de 3 de noviembre de 1956, sobre una fómula polinómica que permitia optimizar los resultados de las reuniones ministeriales midiendo factores tales como el número de miembros influidos por la presión exterior de otros grupos, distancia en centímetros entre dos miembros que se sientan al lado uno de otro, la paciencia del presidente medida a la escala de Peabody, promedio de la presión sanguínea de los más viejos... Y concluia con seriedad que la Comitología se enconiraba en fase muy avanzada de desarrollo. La resena lleva las iniciales L.R.

45 Salvador Panikl: en Conversaciones en Madrid, Kairós 1969, pág. 310, hace la siguiente semblanza de su amigo, entonces ya Ministro Comisario del Plan de Desartollo, que puede resultar interesante a efectos de valorar las consecuencias del compromiso político que habia asumido desde diciembre de 1956: -lópez Rodó entiende que las sociedades industriales son muy frágiles y que la inestabilidad politica resulta cara. De ahi que, aunque de talante liberal $y$ moderado, preste su consenso a 
una políica de autoridad que no quiere veleidades con el orden público. Espana tiene que llegar a los mil dólares de renta per capita; después ja veremos.

"En 1958 García Dr: Enjtirkia labía manifestado en el prólogo de la edición española de la obra de J. D. Moow:y, Principios de organización (nambién editada por el Instituro de Estudios Politicos), cuando, al parecer, pretendia que todos los focos del movimiento de reforma administrativa que se habia empezado a desarrollar en nuestro pais, no iluminaran únicamente el espacio que ocupaba la Secretaria General Técnica de la Presidencia del Gobierno, cuyo titular era su colega de Derecho Administrativo y antagonista en estas cuestiones, López Rodó, que: Esta Ciencia no juridion de la Adıninistración... está siendo urgentemente promovida por todos los paises, especialmente con vistas a las reformas administrativas que las nuevas funciones del Estado demandan por doquier. En Espania el equipo de administrativistas del Instituto de Estudios Políicos no cree que se le discuta el relativo mérito de laber iniciado la atención a estas técnicas ) de haberlas estudiado más tarde, en las páginas de la Revista de Adiministración Pública, primero, $y$, luego, ya como disciplina sistemática, en los beneméritos Cursos de Administración Pública desarrollados desde 1953.

17 En cuanto a la paradójica tolerancia del régimen franquista con alguna de esias lejes - por ejemplo, la de la Jurisdicción Contencioso-Administrativa-, no está de más

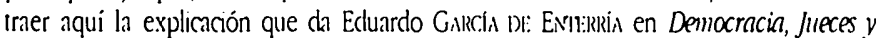
control de la Administración, Civitas 1995: .Por una parte, el propio régimen tenia entonces especial interés en presentar una faz de Estado de Derecho. en el sentido (que em por cierto, el de los autores clásicos alemanes más relevantes del XIX y XX), de un Estado con Derecho Adnunisiraivo pero sin derechos fundamentales... Pero, en segundo lugar... resullaba que el desamollo de una jurisdicción contencioso-adminisistrativa extensa no creaba grandes problemas politicos, precisantente porque venia en refuerzo de la propia legalidad del Estado y del orden y control de la Administmaión.

16 Sobre la oposición de la Secretaria General del Movimiento o del Instiruto de Estudios Políicos a la creación de la Secretaria General Técnica de la Presidencia del Gobierno, ver lavier Tusi:LL, ob. cit., píg. 227.

19 Lóli:: Roló, ob. cit., págs. 81-88.

"Asi lo reconoció el propio Carrero Blanco en su discurso ante las Cortes Espanoolas el 15 de julio de 1957, con motivo de la presentación precisamente del projecto de Ley de Régimen Juridico de la Adminisiración del Estado, Diario de Sesiones $n^{2} 563$, pág. 11448: (La Ley) constiluye en realidad un conjunto orgánico con cuanto se establece en el Decreio-Ley: de 25 de febrero de 1957. Ambos texios pudieran haber sido promulgados conjuntamente, pero Su Excelencia el Jefe del Estado no quiso hacer uso de su faculaad legislativa más que en el mínimo indispensable que las circunstan. cias del caso requerian.

"Ver lavier Tusi:al. ob. cit., pág. 234, en la que destaca la repercusión que esta función supuso en la pricrica a diferencia de lo que habia sucedido en julio de 1951 , en cuanto al modo de trabajo del Gobierno: - Las insirucciones enviadas inmediatamente después de la formación del nuevo Gobierno establecian la periodicidad de las reuniones del Consejo de Ministros y de las Comisiones Delegadas, la distribución entre los distintos ministerios de los antecedentes de las disposiciones que se presentaran a la consideración del Consejo, el papel central de Presidencia en la determinación de orden del dia de las reuniones y el repano de documentación previa j; en fin, su res. ponsabilidad en la confección de las actas. Ésta fue una novedad esencial... es necesario recordar que antes de esta fecha no existian estas actas... Esta situación revela de manera clara lo que era el régimen en esa fase inicial, hasta mediados de la déca. da de los cincuenta.

¡2 Paul Prlsion, ob. cil., pág. 825, a propósito de las consecuencias de esta crisis en el reparto de papeles enire Carrero y: López Rodó, mantiene la siguiente opinión: - Como subsecreario de la Presidencia, el siempre leal Carrero Blanco era el principal consejero politico de Franco. Al comenzar el Caudillo a relajar su atención sobre los asuntos cotidianos, Carrero Blanco, que compartia todos los prejuicios politicos de Franco y parte de su astucia, fue asumiendo gradualmente ciertas tareas propias de un primer ministro. López Rodó, a su vez consejero político de Carrero Blanco, consolidaria esa tendencia mediante la creación de una maquinaria administrativa destinada a afrontar los complejos problemas técnicos de una economía moderna.

5. Ver Mariano BatiNa DI:L ALCiłık, Organización administratila, Tecnos 1984, pág. 31. Bilixi comenta: Hasta 1957 la falta de claridad de la legislación y el carácter de Ministro del Secretario General del Novimiento, y en ocasiones del Delegado Nacional de Sindicatos, hacia que estas organizaciones se comportaran en la práctica como Departamentos ministeriales. Sólo desde la fecha indicda queda claro el carácter de Mlinisiro sin manera del Secretario General del Movimiento, y por unto la organiza- ción de éste ( $\mathrm{f}$ la de los Sindicatos) deja de formar parte de la Administración central ocupando una posición singular.

" Ver ob. cit., págs. 107 y 108. Sin pasar por alto las suspicacias del procumdor Paulino Marlinez Hermosilla que llegó a afirmar: Bajo la humilde apariencia de una simlple ley adiministrativa, se nos presenta hoy un proyecto que viene a alterar profundamente las bases del Régimen. López Rodó ya habia comenzado a suscitar serios recelos y temores en ciertos ambientes del Movimiento Nacional

s) Diario de Sesiones $n^{2} 563$, págs. 1148 a 11460, correspondiente al Pleno de 15 de julio de 1957.

* En la relación sesgada que hizo de desdichados acontecimientos hisióricos desde la muerte de Fernando VII hasta julio de 1936, llegó a contabilizar once cambios de régimen; tres destronamientos de rejes; dos destierros de regentes; cuatro atentados contra monarcas; dos repúblicas; ocho Constituciones; dos dictaduras; tres guerras civiles; : 109 gobiernos. Pero lo más patético es que en esia nómina de desasires hisióricos también se refirió a los asesinatos de cuatro Presidentes del Gobierno: Prim, Cánovas, Canalejas y' Dato.

"Lôli: Ronó en sus Memorins, pág. 134, cita nominatim a los caledráticos de Derecho Adninistrativo Manuel Ballbé Prunés y lesús González Pérez con los que me reuni varios fines de semana en el .Hotel Felipe Il. de El Escorial.

is En Franco visto por sus ministros, Planeta 1981, pág. 168, López Rodó reconoce que junto con Navarro Rubio y Ullastres, lo que pretendian era macionalizar la economía y conseguir el may or incremento posible del Producio Nacional. Y añade: Pero a la vez me dediqué a la politica pura (sic), y tuve una intervención importante en el proceso sucesorio.

39 Ver ob. cit., pág. 175.

(1) Ver ob. cil., pág. 134. Sin embargo, en la publicación de la Secretaria General Técnica de la Presidencia del Gobierno, de julio de 1964, La reforma administrativa en Esparia. Memoria de siete anios de realizaciones, no aparece referencia alguna a los dos textos en el amplio listado de actuaciones que contiene en los apartados dedicados a las reformas orgánicas $y$ funcionales. Ni tampoco en los Anexos en que figuran los textos integros de las principales leyes promulgadas lasta el momento. Lo que no tiene nada de extrano teniendo en cuenta que eran Lejes del Ministerio de Hacienda, $y$ si, por otra parte, atendemos al vicio de la compartimentación de los Ministerios con el que la propia reforma administrativa pretendia acabar.

"Aqui falla la memoria o el archivo de Lópli: Ronó. Lo que se acordó constituir en la reunión del Consejo de Ministros del dia 28 de junio de 1957 fue una Ponencia presidida por el Ministro Subsecretario de la Presidencia (Carrero), e integrada por los Ministros de Asuntos Exieriores (Castiella); Justicia (Iturmendi); Gobernación (Alonso Vega); Educación (Rubio); Obras Públicas (Vigón); Trabajo (Sanz Orrio); Información y Turismo (Arias Salgado); ; Secreario General del Movimiento (Solis), para estudiar la orientación política a seguir en orden a la situación actual. No sería amiesgado aventurar que López Rodó pretendiera la constifución de una Comisión Delegada de Ministros, figura que tanto habia patrocinado ; cuja posibilidad ya se habia recogido en el Decreto-Ley del anterior mes de febrero, con la misión especifica de estudiar las nuevas Lejes Fundamentales. Y que asi se lo propusiera a Carrero Blanco. Pero la decisión final fue formalmente más modesta, y se estimó suficiente una Ponencia; lo que no le quita importancia al asunto. Sobre la actividad de esta .Comisión. según lo. Ili: Ronó, ver su ob. cit., págs. 112-115.

(" En el correspondiente Diario de Sesiones, número 589, pág.12242, después del extenso discurso de Franco se hace constar la parafernalia del momento: $\bullet A$ continuación, S.E. el Jefe del Estado se levanió de su sitial ante la Cámara, puesta en pie, y promulgó la siguiente ley Fundamental del Reino. Con más sarcasmo, en -La época de Franco (1939-1975), Volumen I del Tomo XLI de la Historia de Esparia de MENiviv. DH: PIDAL (III. La Administración Pública, a cargo de Miguel Bl:Ltrin VILLALBA), pág. 602, se dice: sin otra iniervención de las Contes que la del aplauso.

(3) No está de más traer aqui las propias manifesiaciones de Lôm\% Ronó, de las que pueden deducirse que fue uno de los principales inspiradores del texto que promulgó Franco en majo de 1958: En agosto de 1957, por encargo de dicha Comisión Delegada del Gobierno Ide nuevo el error, que continúa a lo largo de todo su relatol, elaboré un texto refundido de los Principios del Movimiento Nacional partiendo de los textos originarios de Carrero, Iturmendi, Vigón y Solis, y el correspondiente anteprojecto de Ley Fundamental... Este texto habria de experimentar ulteriores modificaciones. Ya en el mes de ocrubre le di una redacción más concisa que contenia quince Principios, y en noviembre lo sinteticé aún más reduciéndola a catorce. Pero no quedó ultimado hasta el 2 de majo de 1958 en una reunión de dicha Comisión Delegada 
dcl Cobicrno que presidió Fmnco. Pero entre el mes de noviembre de 1957 y mayo de 1958 hay, cntre otms vicisitudes, un tira y afloja a propósito de la forma política del Esiado, entre López Rodó y los representantes de la Secretaria General del Movimienıo, Jesús Fuejo y Julián Pemartin, que pretendian sustinuir la palabra Monarquia por la de Reino, para dejar la puerta abierta al regencialismo que era el mal menor que, hacia cl futuro, estaba dispuesio a aceptar un sector imponante de la Falange. En cunlquier caso, no ofrece duda que la actividad de lópez Rodó en aquella época ja no se circunscribia políicomente a los temas propios de la reforma administrativa. Hacia clarns incursiones en la institucionalización del régimen, que es lo que lógicamentc le importaba más. Lo que debía producir confusión y extrañeza entre quienes ienian un concepto más estricto y limitativo de la reforma de la Administración, y vcian difícil su compatibilidad con cuestiones de más alıa política. Ver Lópł: Ronó, ob. cit., pígs. 139-144.

"Ver Franco visto por sus ministros, píg. 39.

G De la colocación del personal de esios organismos suprimidos en las unidades convencionales de la Aduninistración Central del Estado, se encargó la Comisión Liquicladori de Organismos, presidida por el Oficial Mayor de la Presidencia del Gobierno.

"Si repasamos la nómina de colaboradores adscritos a la Secretaria General Técnica de la Presidencia del Gobierno, o de los asistentes a la I y II Semanas de Estudio sobre la Reforma Administmativa que se celebmron en Santander en los meses de julio de 1957 y 1958, veremos que están presentes funcionarios de lodos los cuerpos más prestigiosos de los Ministerios: letmdos del Consejo de Estado; abogados y economislas del Esıado; técnicos de Administración de Obras Públicas, Gobemación e Información y Turismo, principalmente; letrados del Ministerio de lusticia; ingenieros de todas las ramas; profesores universitarios; jefes de los tres Ejércitos...

${ }^{67}$ En aquella época Antonio Carro Martinez tuvo bastante relación con Carlos Arias Navarro, a la sazón titular de la Dirección General de Seguridad. Cuando en enero de 1974 fue designado Presidente del Gobierno, después de la muerte de Carrero Blanco, nombró Ministro de la Presidencia a Antonio Carro.

${ }^{*}$ A última hom, en noviembre de 1962 , lubo que cambiar todas las tapas de las monografias que se habian ediado con los inabajos y estudios preparados por las $\mathrm{Co}$ misiones y Ponencias, en las que figuraba como único título el de I Plan sólo de Desarrollo Econónicico

(4) Ver anterior nota 24 a pie de página.

"En el número 93 de Documentación Administratila, correspondiente a septiembre de 1965, se publica una conferencia de HI:RNíND)l:: Suspl:Lsyo pronunciada en un Seminario de la O.C.D.E. colebrado el mismo mes en Alcalá de Henares, que lleva por titulo Panomma actual de la refomma adminisımativa. Además de los tópicos concepuniles que expuso sobre la reforma administrativa, se refirió a los problemas que plinteaba en aquel momento. Entre ellos aludió a la excesiva compartimentación de la Aduninisımción que dificulta la coordinación entre los Ministerios, a la necesidad de una norma legislativa previa que determinara genéricamente los principios y fines de la reforma, $y$ la necesaria existencia de órganos permanentes de reforma que gamnnizaran su continuismo. También apuntó como problemas concretos el de las esInclumas administmativas territoriales, la proliferación de entidades estatales autónomas, la incorponción de técnicas de racionalización del imbajo, y la promoción social de los funcionarios. De una lectura atenta de las palabms del Secretario Gcneral Técnico de la Presidencia del Gobiemo en aquella oportunidad, fácilmente se podria concluir que, efectivamente, faltaban unos objerivos principales bien definidos que articulamn y dieran coliesión a todo el movimiento. Orm cosa es que la solución en ese momento pudiem alcanzarse mediante la promulgación de una ley que los aprobam. Que cm lo que precisamente habia sugerido hacia nueve años el entonces Ministro de Agricullum, cuando se estaba preparando el Decreto-ley que creó la Secrelaria Gencral Técnica de la Presidencia.

"Sc le ha adjudicado al entonces Ministro de Obras Públicas, lorge Vigón, la siguicnic frmse: la libernad empieza a partir de los ochocientos dólares anuales de ingresos mínituos de cada ciudadano. La renta per capita rondaba los trescientos dóliares anuales al inicio de la década de los sesenta. El propio Lópliz Ronó disputa con Salvador PinNkl:k la autoria de orma frase similar: Espana tiene que llegar a los mil dólares de renta per capila; después ya veremos. Ver ob. cit., pág. 310.

" los aparados 14 y 15 del Informe del Brnco Mundial de Reconstricción y Fomen10, ediiado por la OCYPE 1962, págs. 17 ; 18, se refieren a la organización para el desarrollo. Dicen lo siguiente: $\cdot 14$. La tarea de llevar a cabo un progmma de desarroIlo cs muy compleja y requiere una organización central adecuada. Exige también una firme determinación de trabajar conjuntamente a favor del progmma por parte de todas las secciones y ramas de la Administración. $\cdot 15$. El Gobierno ha dado los primeros pasos para facilitar semejante organización al crear en la Presidencia el cargo de Comisario del Plan de Desarrollo Económico, con facultades para actuar por cuenla de la Comisión Delegada de Asuntos Económicos, asegurando la coordinación entre Ministerios, Sindicatos e intereses privados, y para centralizar la considemción de los problemas del desarrollo económico. A esta misma conclusión se habia llegado en la reunión de Lisboa del Instituto Internacional de Ciencias Administrativas, del 11 al 16 de septiembre de 1961, en el sentido de que rodos los paises se habian visto obligados a montar la oportuna organización administrativa que cuidase de dirigir el proceso de su crecimiento econónluico.

7. Ver ob. cit., págs. 309-311.

74 La reuniones de esta Comisión Delegada del Gobiemo tenian lugar en viemes alternos; los otros se dedicaban a las reuniones del Consejo de Ministros. No era inusual que se tomaran decisiones gubernamentales en estas reuniones más restringidas, y que al viernes siguiente se diera cuenta de las mismas en la reunión plenaria del Consejo de Ministros. Como tampoco era inusual que se tratamn temas y asuntos que no se referian exclusivamente al desarrollo económico.

` La plantilla presupuestaria inicial del Cuerpo Economistas del Estado ema de 24, y en diciembre de 1962 se aumentó a 36. Fue una gran fuente de reclutamiento de allos cargos (ministros, subsecretarios, directores generales y secretarios genemles técnicos, directivos de empresas públicas y de la banca oficial). Los nombres de Agustin Cotormuelo Sendagorta (el número 1 -decano- del escalafón), Alberto Monreal Luque, Tomás Galán Argüello, Javier Irastorza Reruelta, José Ramón Álvarez Rendueles, Manuel Antonio de la Riva, Angel Lerena, Francisco Gallego Balmaseda, entre otros, son expresivos del elevado nivel profesional de los funcionarios que fueron ingresando en el Cuerpo de Economistas. Y que López Rodó adscribió a la red central y ministerial de su sistema para el desarrollo económico.

${ }^{7}$ En Documentación Administratiia n² 28 , pág. 11.

$\pi$ Según testimonio de Agustín de Robledo y Molina, funcionario del Cuerpo Técnico-Administativo de la Presidencia del Gobierno, y entonces Jefe del Servicio de Administración Financiera.

${ }^{78}$ Años más tarde, el propio HERNAiNiDE SMMPILAYO en la conferencia antes citada en la nota 60 , reconoció expresamente que el sistema de cuerpos especiales de funcionarios adscritos a determinados ministerios favorece la rigidez, que puede ser paliada, en parte, por el reforzamiento del Cuerpo General de la Administración, cuja función es administrar y llevar a cabo funciones comunes. Estas manifestaciones hechas en septiembre de 1965, a los nueve meses de la constitución formal del nuevo Cuerpo Técnico de Administración civil del Estado, fueron cuando menos escasamente oportunas para diluir los recelos y prevenciones que su creación había supuesto entre los cuerpos especiales que entonces dominaban los Minisierios.

" MLNENEIIE PIDML, Historia de Esparia Tomo XLI, III La Administración, dirigido por Miguel Belirán Villalba, Espasa Calpe 1996, pág. 599.

8) El mismo autor, Bl:IIRin VILLA.lBA, ob. cit., págs 598 y 599 evalúa de la siguiente manera la reforma administrativa de los tecnócratas: •Aunque frustrada en buena parte de sus propósitos, la reforma en su conjunto supuso una visible renovación de la Administración pública, llevada a cabo con criterios de aumento de la eficiencia y de racionalización de la actividad administrativa. Entre otras cosas implicó una en cieno modo apresurada y superficial recepción de las técnicas más básicas del management de organización y métodos (las famosas $O \& M$ ) y de recetas. de la Escuela de Relaciones Humanas; y con su orientación pragnática y tecnocrítica contribujó a eludir los problemas políticos que tenia planteados un régimen autoritario anticuado que se ajustaba mal con una sociedad que estaba configurándose rápidamente como moderna y desarrollada.

${ }^{81}$ Si bien el regreso del general Muñoz Grandes, antiguo jefe de la División Azul y de manifiesta adhesión a la Falange, nada menos que como Vicepresidente del Cobiemo, podia suponer un inconveniente para el equipo de la Presidencia del Gobierno, se amplió su influencia con tres nuevos Ministros de clam disciplina tecnocrática: Lora Tamajo, en Educación Nacional; López Bravo, en Industria; y Romeo Gorria, en Trabajo. A esto había que añadir la salida definitiva de Arrese (fue sustituido por otro falangista sin carisma alguno, Maninez Sánchez-Arjona) y la llegada de Fraga Iribarne a Información y Turismo. Como senala Ricardo bl: IA Cil:R's en Historia del franquis. mo, págs. 215-216, Procedia éste de la Falange modemda... había sido secretario general técnico en la época de Ruiz Giménez... generacionalmente se orientaba hacia Europa y a una decidida liberalización del régimen. 


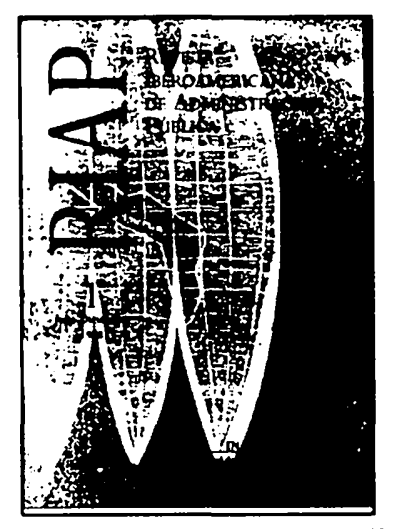

La Revista Iberoamericana de Administración Pública, RIAP, es una nueva publicación semestral del Instituto Nacional de Administración Pública de España a través de la cual el INAP, continuando su tradición de acercamiento y colaboración con los países iberoamericanos, pretende crear nuevos vínculos de relación y cooperación entre las Administraciones Públicas de España e Iberoamérica.

Concebida como un foro abierto para la cooperación y el intercambio de información, opiniones y experiencias en el ámbito Iberoamericano de la Gestión Pública y las Ciencias de la Administración, la Revista Iberoamericana de Administración Pública, cuenta con un Consejor Rector Institucional presidido por el Ministro de Administraciones Públicas de España y con un Comité Científico integrado por destacados profesores e investigadores universitarios de Iberoamérica y de España.

La nueva Revista cuenta con un Índice estructurado en tomo a cuatro Secciones: Artículos, Experiencias, Noticias y Documentos, dentro de los cuales tienen cabida desde las reflexiones doctrinales, hasta las crónicas de actualidad, el intercambio de informaciones sobre experiencias y actividades y la publicación de dossieres y documentos de interés mutuo.

Con todo ello, y mediante esta nueva publicación, el INAP de España desea continuar sus líneas de actuación respecto de Iberoamérica en las que a su misión institucional se le unen su vocación y su compromiso de presencia y colaboración con sus Administraciones Públicas.

\author{
Director \\ D. Enrique Álvarez Conde \\ Secretario \\ D. Jorge Urosa Sánchez \\ Coordinación \\ Centro de Publicaciones del INAP
}

\section{Edita:}

MINISTERIO DE ADMINISTRACIONES PÚBLICAS

Instituto Nacional de Administración Pública

\section{Suscripciones y Administración:}

Instituto Nacional de Administración Pública

Centro de Publicaciones

Atocha, 106. 28012 Madrid

Teléfono: $913493115-3235$

Fax: 913493287

E-mail: publicaciones@inap.map.es

\section{Precios:}

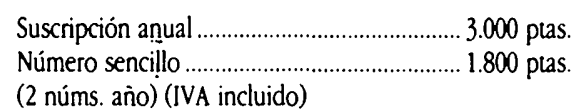

